\title{
Multi-sectoral impact assessment during the 1st wave of COVID-19 pandemic in West Bengal (India) for sustainable planning and management
}

\author{
Biraj Kanti Mondal ${ }^{1} \cdot$ Satiprasad Sahoo ${ }^{2}$ (1) $\cdot$ Poulami Paria $^{3} \cdot$ Subrata Chakraborty $^{4} \cdot$ Abdullah M. Alamri $^{5}$
}

Received: 28 September 2021 / Accepted: 2 November 2021 / Published online: 15 November 2021

(c) Saudi Society for Geosciences 2021

\begin{abstract}
With the advancement of globalisation, urbanisation and environmental change, the outbreak of the Coronavirus disease 2019 (COVID-19), as an infectious disease, has become a global threat. The entire world is continuously trying to adapt to the pandemic situation due to the sudden outbreak of COVID-19 and the lockdown phase, which has not been faced before. The fear of infection by such an unknown virus and the epidemic transformed the built-up environment and impacted various sectors of lives and livelihoods, which must be assessed in spatial perspectives. The objective of this research is to assess the multisectoral impact due to the COVID-19 pandemic. Thus, it is designed to inspect seven essential sectors, namely, the economy, employment, education, transport, travel and tourism, health and environment sector-wise impact assessment of the West Bengal state of India. Taking the required COVID-19 data from the government website of India (http://www.covid19india.org; https:// www.mygov.in/corona-data/covid19-statewise-status) and West Bengal (https://covidindia.org/west-bengal), a methodology is proposed on an integrated framework for the multi-sectoral impact assessment. The study concentrates on West Bengal, as no study exists on the multi-sectoral impact assessment due to the COVID-19 pandemic during the 1st wave, especially using the geospatial platform. The economy, employment, education, transport, health, tourism and environment multi-sectors of West Bengal are selected in this research, as these sectors have built the economic, sociocultural and environmental pillars of the state. All these sectors have been seriously affected, and the nature of the impact is diverse and large. Before the vaccine comes into the hands of the common people of West Bengal and in a broad sense in India, the awareness should be increased at the grass-root level to fight against the pandemic situation and even after the post-COVID era. The application of geospatial technology used for the mapping and analysis of COVID-19 affects the related database to tease out the multidimensional study, which aims to plan future road maps, search for answers and learn to add further security to overcome the future virus attack.
\end{abstract}

Keywords COVID-19 $\cdot$ Multi-sectoral $\cdot$ GIS $\cdot$ Impact assessment $\cdot$ Sustainable management

Communicated by: Biswajeet Pradhan.

Satiprasad Sahoo

satispss@gmail.com

1 Department of Geography, Netaji Subhas Open University, Kolkata, India

2 Department of Geography, Jadavpur University, Kolkata, India

3 Department of Zoology, Midnapore College (autonomous), Midnapore, India

4 The Centre for Advanced Modelling and Geospatial Information Systems (CAMGIS), Faculty of Engineering and Information Technology, University of Technology Sydney (UTS), Sydney, NSW 2007, Australia

5 Department of Geology and Geophysics, College of Science, King Saud University, Riyadh, Saudi Arabia

\section{Introduction}

Coronavirus disease 2019 (SARS-CoV-2) (COVID-19) is a ribonucleic acid virus and a mild-to-moderate respiratory tract infection (Schulte-Schrepping et al. 2020). It is marked by the occurrence of neutrophil precursors and is highly variable according to clinical data. It has also impacted patients with end-stage kidney disease ( $\mathrm{Ng}$ et al. 2020). However, in the first week of March 2020, COVID-19 was identified as a pandemic, according to the World Health Organisation (WHO). Sector-wise (e.g. education and tourism) human activities were highly impacted by COVID-19 when the government of India implemented a nationwide lockdown during the 1st wave in the last week of March 2020 (Chowdhuri et al. 2020). This decision affected the food supply-chain 
systems all over the country that continued to unfold. Moreover, the stakeholders of diverse sectors started optimising the adjustment with the situation and trying to continue and contribute as much as possible to the sustainable development of the allied sectors. Thus, sector-wise impact assessment is required for future sustainable planning and management purposes. No study is available on the multi-sectoral (e.g. economic, education and employment) impact assessment by COVID-19. Hence, the present research proposes a methodology on an integrated framework for the multi-sectoral impact assessment by the COVID-19 pandemic using a geospatial platform.

The first COVID-19 case in India was identified in Thrissur, Kerala, on January 30, 2020. It was an infected person who returned from Wuhan in China. From then until March 9,2020 , the total number of infected cases was restricted to six; thereafter, the number of confirmed cases increased and reached 50 on March 11, 2020. Since then, the total number of confirmed cases started to fly at a fast rate and reached 11,485 on March 31, 2020. The nationwide lockdown was implemented in India far before the virus reached the community transmission stage. However, several states, such as Maharashtra, Tamilnadu, Delhi, Gujarat, Rajasthan, Madhya Pradesh and West Bengal, are the states where the maximum number of cases was reported. In addition, the metropolitan cities within the territory of the mentioned states became the most affected, as the number of positive cases was reported continuously in those areas. The daily number of confirmed COVID-19 cases is available on the government website (https://www.mohfw.gov.in) and on COVID-19 Tracker in India (http://www.covid19india.org), whereas the state-wise data can be found on https://www.mygov.in/corona-data/ covid19-statewise-status. In the case of West Bengal, the data are available on the state government website (https:// covidindia.org/west-bengal).

In December 2019, the Coronavirus spread from the city of Wuhan, China (Bukhari and Jameel 2020), and affected the whole world; people from 216 countries lost their lives due to the respiratory tract infection caused by COVID19. Within a short period, the virus transformed into an extraordinary catastrophe worldwide, and the WHO considered this infectious disease a pandemic, as it estimated 367,166 deaths by May 31,2020. With such conditions, the new term 'infodemic' coined by the WHO came out; news, information and data that circulated through social and electronic media also traumatised people. With the sudden outbreak of such a deadly virus, several governments failed to control the situation and the deficiency of readiness to fight against it. The situation became aggravated in developed countries, whereas in developing countries, such as India, the situation was attempted to be controlled by implementing complete lockdown and imposing strict guidelines. However, 182,143 positive COVID-19 cases were identified, including 5,164 deaths at the end of the lockdown on May 31, 2020. The infection rate and death rate jumped at a high rate and intensity throughout the country. The recovery rate at the national level was $48.18 \%$ [Indian Council of Medical Research report], whereas the state-wise disparity was huge even though the complete lockdown throughout the country ended on May 31, 2020.

West Bengal is the sixth-largest state of India, located in the eastern part, sharing an international border with Bangladesh and national boundary with several states, contributing almost $8 \%$ of the total population of the country. The state capital, that is, Kolkata, is the only mega city of eastern India, having high population density and controlling a huge hinterland region for economic and regional cooperation with Southeast Asian countries. The state's physical landscape, economic base, industrial support, mineral extraction, import and export businesses and environmental beauties attract several tourists from national and international destinations throughout the year, thereby strengthening the state's supported transport and communication sectors and related travels and tourism sectors (Bose 2015; Sarkar et al. 2020; Rumbach et al. 2017; Karar et al. 2006; and Bera et al. 2020). All these factors were discontinued and adversely affected due to the sudden spread of COVID-19 in the state. Hence, we focus on the 1st wave of the situation and thereafter work out this multi-sectoral and multi-dimensional attempt along with health assessment. Note that education sectors are designed accordingly.

The main goal of the current effort is to identify and assess the impact of the COVID-19 pandemic on the diverse sectors of a state, that is, West Bengal of India, during the 1st wave of the pandemic and subsequent lockdown measures. To fulfil the objective, seven essential sectors (i.e. economy, employment, education, transport, travel and tourism, health and environment sector-wise impact assessment) are selected. Studies that have been published so far mostly concentrate on the health hazards, economic and environmental effects and related issues in a comparatively large region. Hardly any research has been published focusing on multi-sectors and using the geospatial platform; both of which are developed and utilised in the current study. The novelty of the current work is that it assesses the impacts of COVID-19 on multisectors in a multi-dimensional attempt highlighting the intra-sectoral shocks. Moreover, the application of geospatial technology used for the mapping and analysis of the COVID-19 impact along with the use of secondary information is a new kind of effort that has been made in the present study. The major drawback of the present work is that it only emphasises the selected sectors and lacks the incorporation of some desired relevant data. Moreover, the expulsion of primary survey data of all the sectors into the research can be mentioned as a research gap and a scope of future research output. 


\section{Materials and methods}

The study focuses on the state of West Bengal of India (Fig. 1), which has been severely impacted by the outbreak of the novel coronavirus. The state belongs to the eastern part of the country, having many urban parts. Kolkata, located by the bank of Hooghly River, is the megacity and capital of the state. The latitudinal and longitudinal extensions of West Bengal are $21^{\circ} 25^{\prime}$ North to $27^{\circ} 13^{\prime}$ North and $85^{\circ} 50^{\prime}$ East to $89^{\circ} 50^{\prime}$ East, respectively. The state has a total area of $88,752 \mathrm{~km}^{2}$. It shares its state boundary with Assam, Sikkim, Odisha, Bihar and Jharkhand states and international boundary with Bangladesh, Nepal and Bhutan. The state has 23 districts and almost all had positive COVID-19 cases. The urban part of the state was first infected and severely affected compared with its rural part. Kolkata, having the maximum number of hospitals, became the prime centre for the testing and treatment of COVID-19 patients. The sector-wise study of the state has been conducted, aiming for impact assessment and sustainable management search, especially the execution and formulation of proper strategic planning against COVID-19 in the post-COVID-19 phase. The current attempt is designed to assess the hypothesis that the impact of the COVID-19 pandemic and related lockdown on the seven selected sectors of West Bengal is negative and multi-faceted but is positive in the case of the environment. Therefore, the study concentrates on the following research questions: (1) How was the COVID-19 situation in India and West Bengal? (2) What were the active cases, recovery rates and death cases in India and West Bengal? (3) How did the districts of West Bengal get affected due to the COVID-19 pandemic? (4) How did the economic and related sectors got affected and how did they manage to recover? (5) What were the situations of health, education and infrastructural sectors? (6) Did the environmental conditions deteriorate or improve due to the lockdown?

The spread of COVID-19 in West Bengal was drastic and multi-faceted, as the state has a large population base and over-dependency on the capital city of Kolkata for various purposes. According to the latest census data (i.e. 2011),

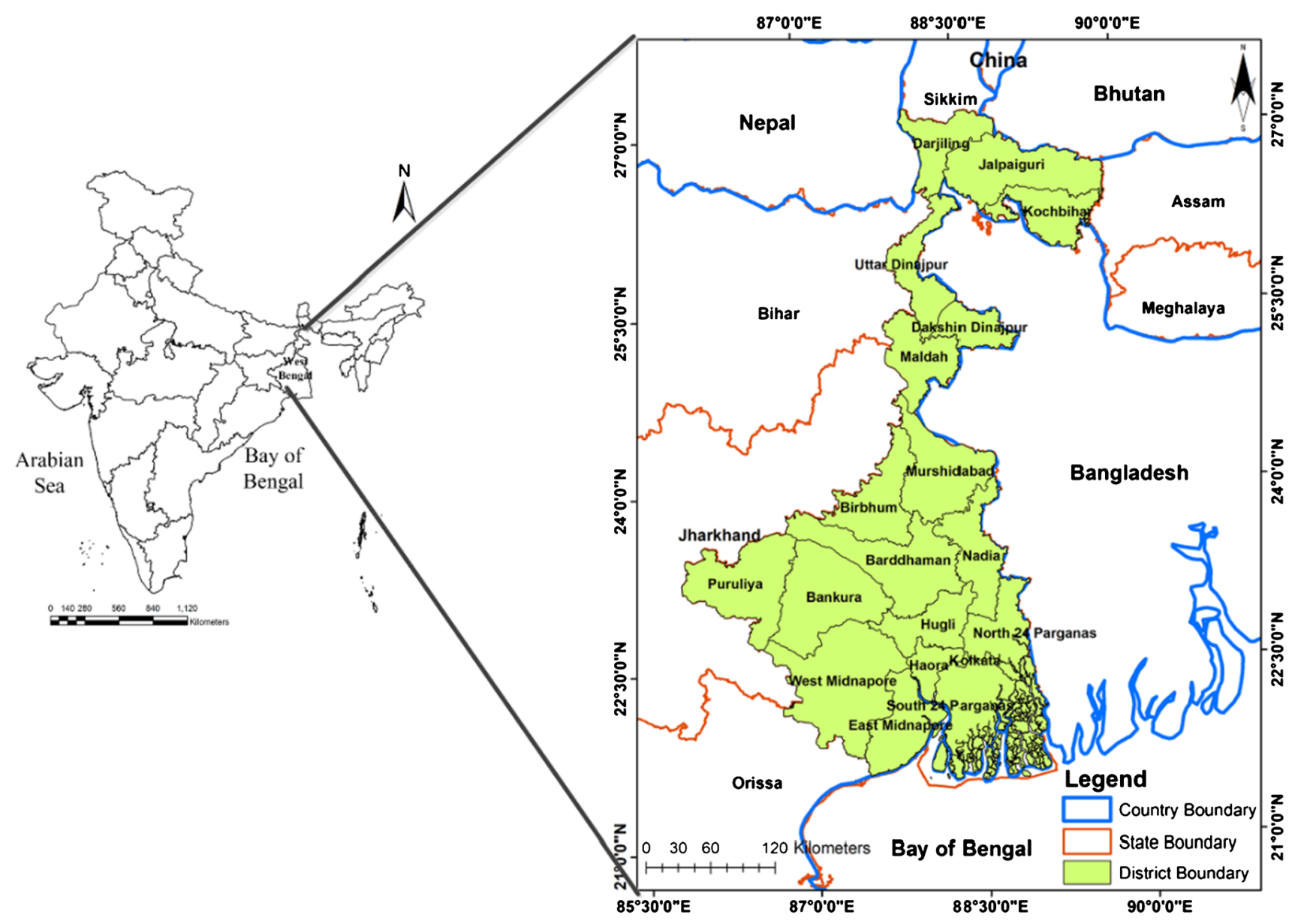

Fig. 1 Location Map of West Bengal 
the total population of West Bengal is 91.3 million, which constitutes $7.54 \%$ of the total population of India, and it has increased to approximately 100.9 million in the year 2020 . The population density of the state is also very high (1028 persons $/ \mathrm{km}^{2}$ ), and the population growth was $13.84 \%$ in the census year 2011. Despite the environmental sectors, a strong, adverse and negative impact was observed on economy, employment, education, transport and travel and tourism sectors in West Bengal, only the environment sector improved (Sarkar et al. 2020; Bera et al. 2020). The lack of data of all the selected sectors for statistical analysis and impact assessment was felt during the study. The state managed to cope up with the situation with a good recovery rate and low death rate, but the anomaly is still present in some sectors.

\section{Methodology}

The study followed proper methodological steps with the combination of primary and secondary data. The purposive random sampling techniques were applied for the primary survey to assess the impact on the education system. To fulfil the purpose, two online surveys were conducted (in May 2020 and June 2020) to collect the information regarding the impact assessment of the lockdown and the COVID19 pandemic on school education and the higher education system of undergraduate (UG) and postgraduate (PG) of five universities in West Bengal. Only a few questions were asked to 45 known guardians of school children in the nursery section, and the same questions were asked to 65 known teachers of schools of diverse subjects in secondary and higher secondary sections. Structured questionnaires using the 'Google form' were sent by email and WhatsApp to approximately 250 students, 50 from each university. A total of 216 students provided their complete information, and we took 200 from that for further analysis. Meanwhile, the secondary data and information were collected from various government reports and documents, such as Census of India, Ministry of Health and Family Welfare of Government of India, Health and Family Welfare Department of Government of West Bengal, Central Statistics Office and State Budget Documents. Fig. 2 illustrates the structured framework of the study. The figure describes the sequential steps followed in this research.

\section{Results}

\section{COVID-19 control in India}

In India, after seeing the increasing rate of positive COVID19 cases, Prime Minister Shri Narendra Modi declared a complete lockdown throughout the country for 21 days for

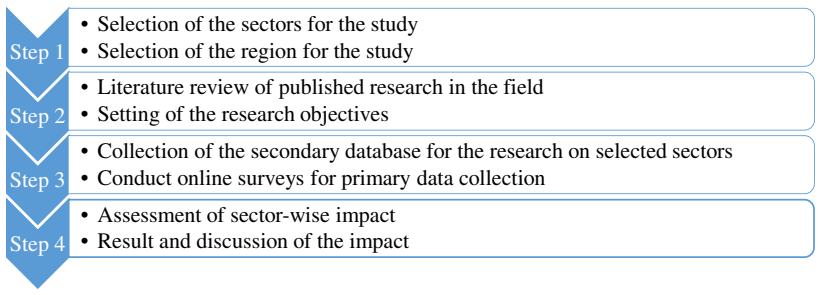

Fig. 2 Structural framework of the study

the first time (phase I) on March 24, 2020. The lockdown was extended for 19 days on April 14 (phase II), continued for additional 14 days until May 17, 2020 (phase III), and further for 14 days until the end of May 2020 (phase IV). These lockdown phases were implemented in most of the states in India by the state governments, and the West Bengal government continued its lockdown for 7-10 days every month until recently. By then, the COVID-19 vaccine was still unavailable in the market, and only positive COVID-19 patients were treated in the hospitals. Nevertheless, the infection rate was minimised with such lockdown because most people were not exposed to the infected people. Therefore, social distancing became the new mantra of life, which could restrict active and positive cases across the country. Apart from the necessary administrative steps regarding social distancing, social gathering, travel restriction, personal protection, mask wearing, home isolation and quarantine were the new norms that people were adapting to. The need of the hour was the availability of the vaccine in the market for the common people, but their awareness and self-protection became effective measures to control the spread of COVID-19.

According to a report from the Ministry of Health and Family Welfare of the Government of India, the numbers of diagnosed patients, active cases, recoveries and deaths in India from March 22, 2020, to May 31, 2020, increased at a fast rate from the middle of April 2020 (Fig. A1 in Appendix 1). The active and recovery rates increased at a comparatively slower and steadier rate than the total diagnosed cases in the mentioned period. The number of deaths was consequently increased, but at an almost steady rate, the total death still made people panic.

However, the number of new cases per day was increasing dramatically and jumped up to 100 in April 2020. It crossed 100 new cases per day in May 2020, crossed 200 per day in the third week of May 2020 and reached 300 at the end of the same month (Fig. A2 in Appendix 1). The rates of diagnosed patients, active cases, recoveries and deaths per day in India also increased. As India is a highly populated country, such an increase was alarming due to the fast-growing number of affected cases. The total number of COVID-19 cases in India increased at a fast pace from July 2020 and 
continued the same trend throughout November 2020, which was quite alarming. The number of daily new cases in India was very high and reached 100,000 per day from the end of September 2020 to the beginning of October 2020 (Fig. A3 in Appendix 1). The number of daily cases in the 9-month period beginning in February 2020 increased and peaked on September 22, 2020, with the trend of infected cases decreasing thereafter.

The total number of deaths was found very high at the end of June 2020 and increased in a fast rate from August 2020, whereas the number of daily deaths was found very high (2,000/day) on June 14,2020 , and again found high on July 14,2020 , onwards but comparatively in a smaller number $(1,000-1,300 /$ day $)$. The trend of new cases was quite higher than that of recoveries up to September 12, 2020, which was countered by the recovery rate, which overcame the number of new cases in September 2020. From then, the recovery rate was improving continuously as we found in the cumulative total numbers of deaths and recoveries over a cumulative number of closed cases in India (Fig. A4 in Appendix 1).

\section{Scenario of COVID-19 in West Bengal}

The Health and Family Welfare Department of the Government of West Bengal confirmed a total of 116,498 positive cases of COVID-19, including 2,428 deaths as of August 16, 2020. The figure reached 449,131 positive cases and 7,923 deaths on November 20, 2020. The first confirmed case of positive COVID-19 in Kolkata was reported on March 17, 2020 (https://covidindia.org/west-bengal). Previous studies revealed that COVID-19 cases were evidently doubling every six days shortly after the end of the complete lockdown in India in May 2020, and West Bengal was not an exception.
Fig. 3 District-wise COVID-19 cases in West Bengal ( Source: Health and Family Welfare Department of Government of West Bengal as of July 24, 2020)

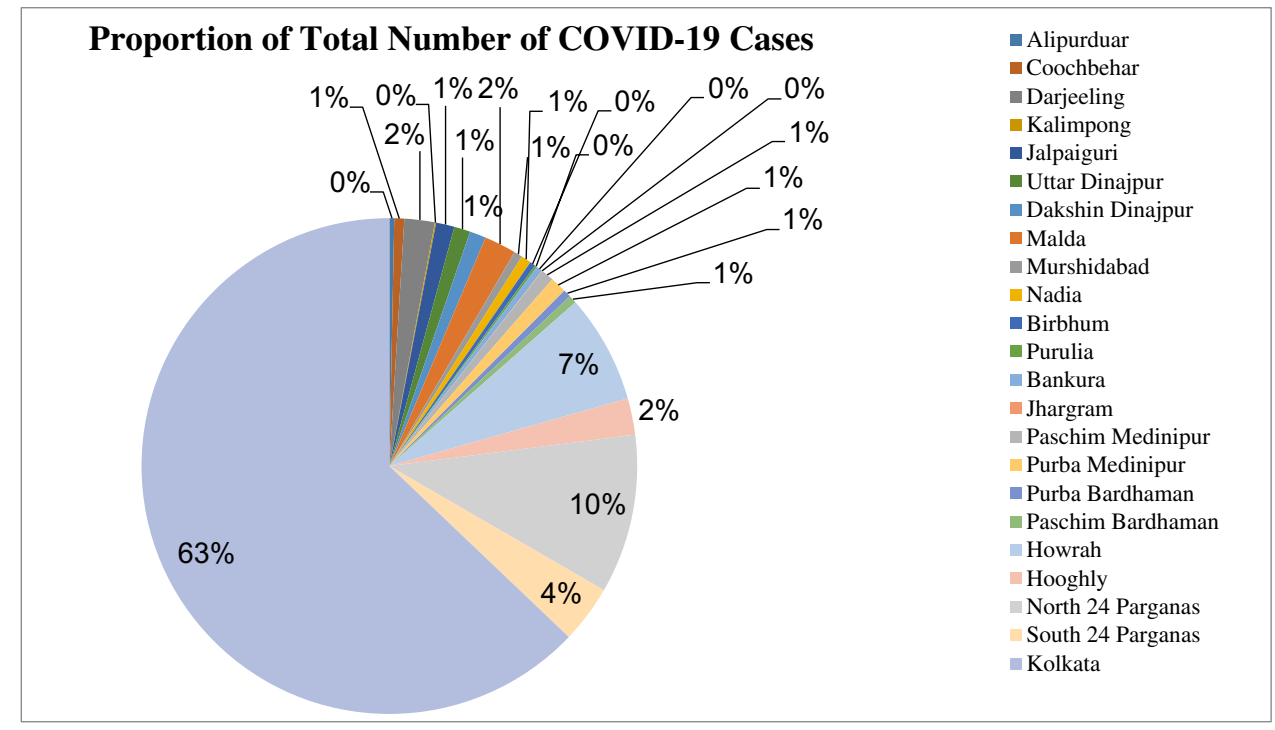

\section{Economy gets further push as top six states no longer lead covid spread}
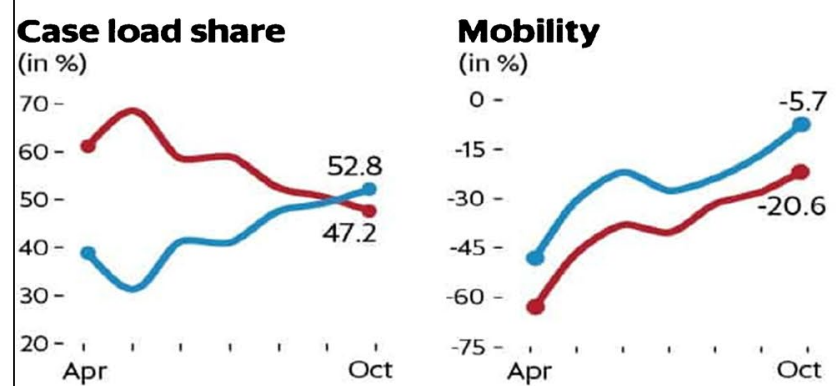

\section{$\leadsto$ Top 6 states (by GSDP)} $\Longrightarrow$ Rest of India

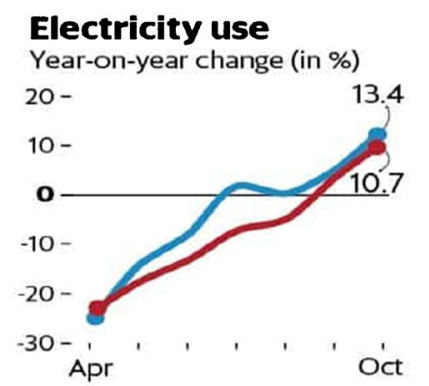

Vehicle registrations

Year-on-year change (in \%)
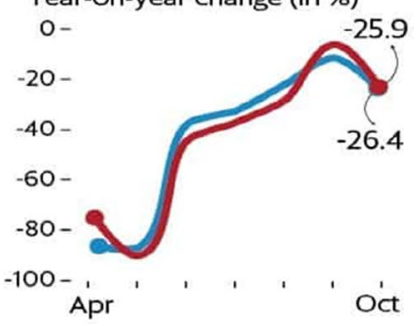

Mobility data (as of 25 October) depicts the percentage gap in footfall at public places as compared with the baseline period ( 3 Jan to 6 Feb). Top six states (by GSDP) are Maharashtra, Tamil Nadu, Uttar Pradesh, Karnataka, Guiarat and West Bengal. Case load refers to new coronavirus cases reported each month.

Fig. 4 Changes of the economy of six states and India during April 2020-October 2020 ( source: State recovery tracker: High GDP states catch up with the rest of India on economic revival, Mint, October 6, 2020) 
The total population of West Bengal crossed 100 million in the year 2020, which was 91.3 million according to the 2011 census and with a balance figure of males and females. The population density of the state is 1,028 people $/ \mathrm{km}^{2}$, with $13.84 \%$ population growth and $81.80 \%$ literacy rate in the latest census year 2011. The state has a sound contribution in the national Gross Domestic Product and the state's Gross State Domestic Product (GSDP) (GSDP is expected to reach 14.44 trillion) in 2020-2021.

According to sources, the percentage of COVID-19 cases to the total population in West Bengal is lower (0.618) than the national average (0.843), but the percentage of deaths to the total number of COVID-19 cases is higher in the state (1.777) than in the national average (1.443) as of January 15, 2021 (Government of West Bengal and Census of India 2011).

\section{Sector-wise impact assessment}

From the literature review, it was revealed that most COVID19-related studies are in the field of medical science or investigate the impact on the environment and health-related issues (Rahman et al. 2020). Therefore, the present study is designed to portrait the impact assessment of diverse and dissimilar sectors to recognise the level and nature of impact for sustainable planning and management. Hence, seven sectors, namely, the economy, employment, education, transport, travel and tourism, health and environment sectors of West Bengal, have been selected. All these sectors are the pillars of sustainability and form the economic, infrastructural, sociocultural and environmental base of the state. All these sectors have been seriously affected by the COVID-19 pandemic, and only the nature is diverse.

In the case of West Bengal, the numbers of deaths, recoveries and active cases from August 2, 2020, to August 16,2020 , reveal that the percentage of death was reduced from 3.4 to $2.1 \%$. Moreover, the recovery rate was continuously improving, but the total number of active cases was increasing; the rate was reduced from 3.8 to $2.7 \%$.
These statistics are quite satisfactory with respect to other states of India that are affected by COVID-19 (Fig. A5 in Appendix 1).

The West Bengal government categorises the districts of the state into three zones on the basis of the COVID-19 cases found in such districts. This categorisation helps the government in controlling the situation against the spread of COVID-19. Moreover, it helps the common people in understanding the situation of COVID-19 cases in the 23 districts of West Bengal. Initially, Kolkata, Howrah, North and South 24 Parganas, Purba Medinipur, Darjeeling and Jalpaiguri belonged to the red zone (seven districts), which signifies most affected areas. Meanwhile, Murshidabad, Nadia, Hooghly, Purba and Paschim Bardhaman and Asansol (five districts) were in the orange zone, which means low to moderately affected. The rest of the districts were in the green or safe zone. Based on the active cases found, the boundary of these red, orange and green zones was changed, and containment zones were added on the basis of highly affected areas that were under strong control and observation (Fig. A6 in Appendix 1).

According to the report of the Health and Family Welfare Department of the Government of West Bengal on July 24, 2020 , the proportion of the total number of positive COVID19 cases was the highest in Kolkata (63\%), followed by North 24 Parganas (10\%) and Howrah (7\%) (Fig. 3). Districts located in the upper portion of Malda were very less affected (only 1-2\%), and other districts were beyond that value, which indicates that the northern parts of West Bengal were quite safe from COVID-19 infection. However, this situation worsened after the arrival of the special train carrying the daily laborers who were working in other parts of the country.

The total number of positive COVID-19 cases in Kolkata was quite alarming as it crossed 65,000 as of July 24, 2020 , followed by North 24 Parganas $(>11,000)$, Howrah ( $>$ $7,500)$, South 24 Parganas $(>4,000)$ and Hooghly $(>2,500)$. Nevertheless, most of the other districts did not cross 1,000 ,
Fig. 5 a Comparison of the economic growth rate of West Bengal vis-à-vis India's GDP (source: West Bengal Budget Documents (MTFP Statement); Central Statistics Office, MOSPI; PRS). b Composition of Major Items Exported (2018-2019) in West Bengal (source: Directorate General of Commercial Intelligence and Statistics, 2020)

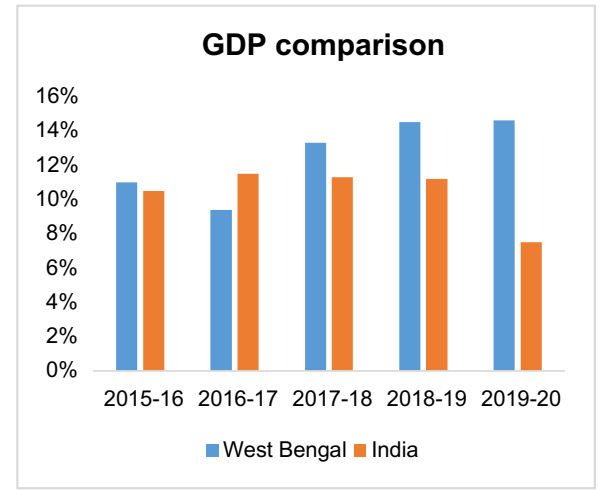

(a)

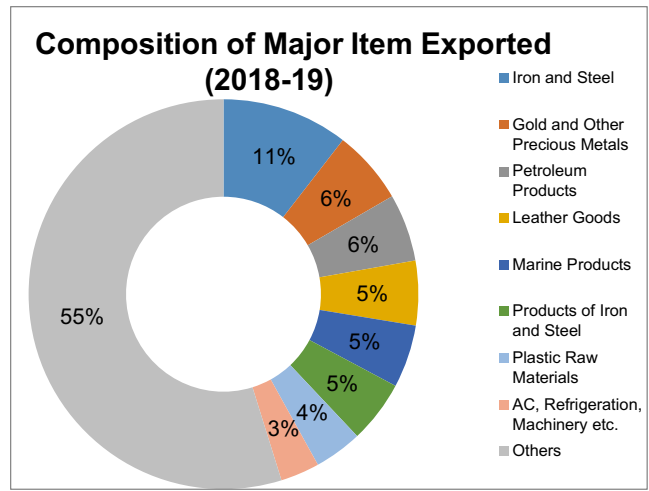

(b) 
and the Jhargram was found to have the lowest number (89) of COVID-19 cases (Fig. A7 in Appendix 1).

The district-wise total numbers of discharge and active cases of positive COVID-19 as of July 24, 2020, were analysed (Fig. A8 in Appendix 1). Amongst the total number of suspected cases tested, a large number was discharged, and comparatively less number was found as active cases. Therefore, the total discharge value was more than the total active case value. These values were quite high in North 24
Parganas, Howrah, South 24 Parganas and Hooghly; moderate in Malda, Darjeeling, Uttar and Dakshin Dinajpur, Purba and Paschim Medinipur; and low in other districts. The districts closely located and associated with Kolkata were becoming more affected than other districts, probably due to their high transport connectivity and accessibility.

The district-wise deaths of COVID-19 positive patients were found very diverse as of July 24, 2020 (Fig. A9 in Appendix 1). Apart from Kolkata, the proportion of death
Fig. 6 a Revenue deficit and fiscal deficit of West Bengal. b Outstanding debt of West Bengal (source: West Bengal Budget Documents (MTFP Statement); Central Statistics Office, MOSPI; PRS)
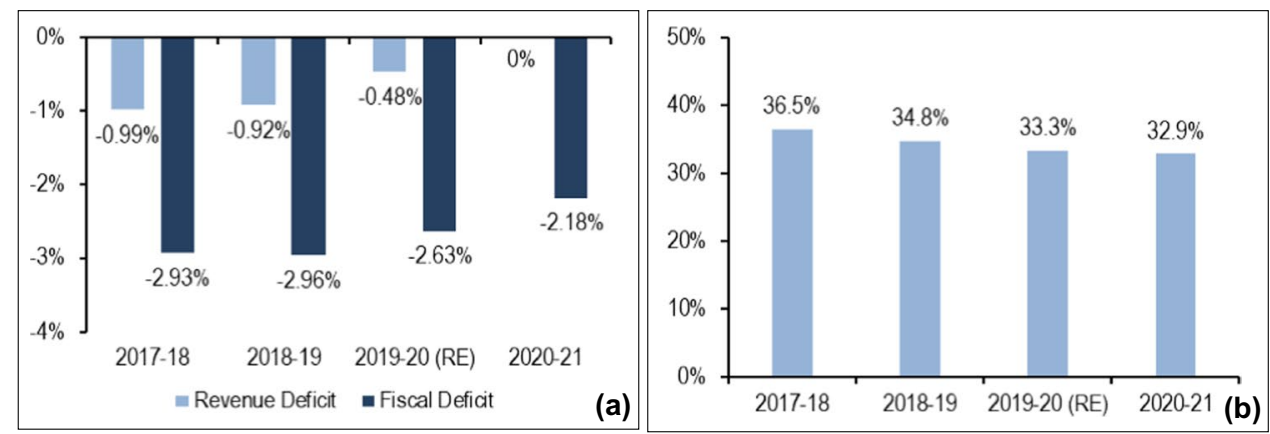

Fig. 7 a Sector-wise expenditure in West Bengal Budget 2020-2021. b Sector-wise proportional changes from RE 2019-2020 to BE 2020-2021

(Source: West Bengal Budget Documents 2020-2021 [Annual Financial Statement, Detailed Demands for Grants]; PRS)

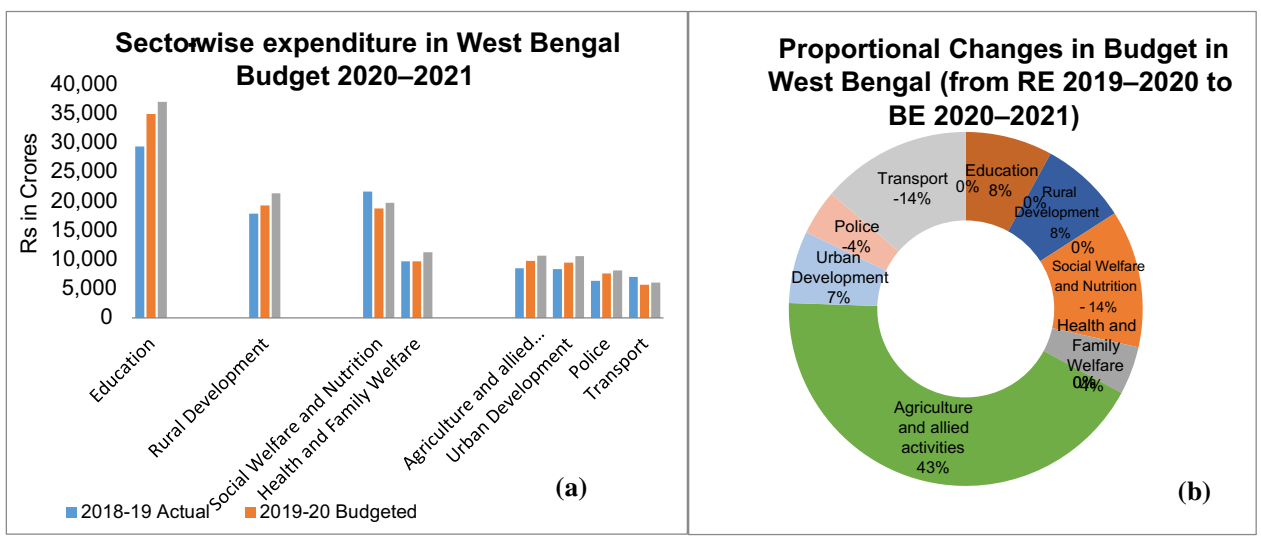

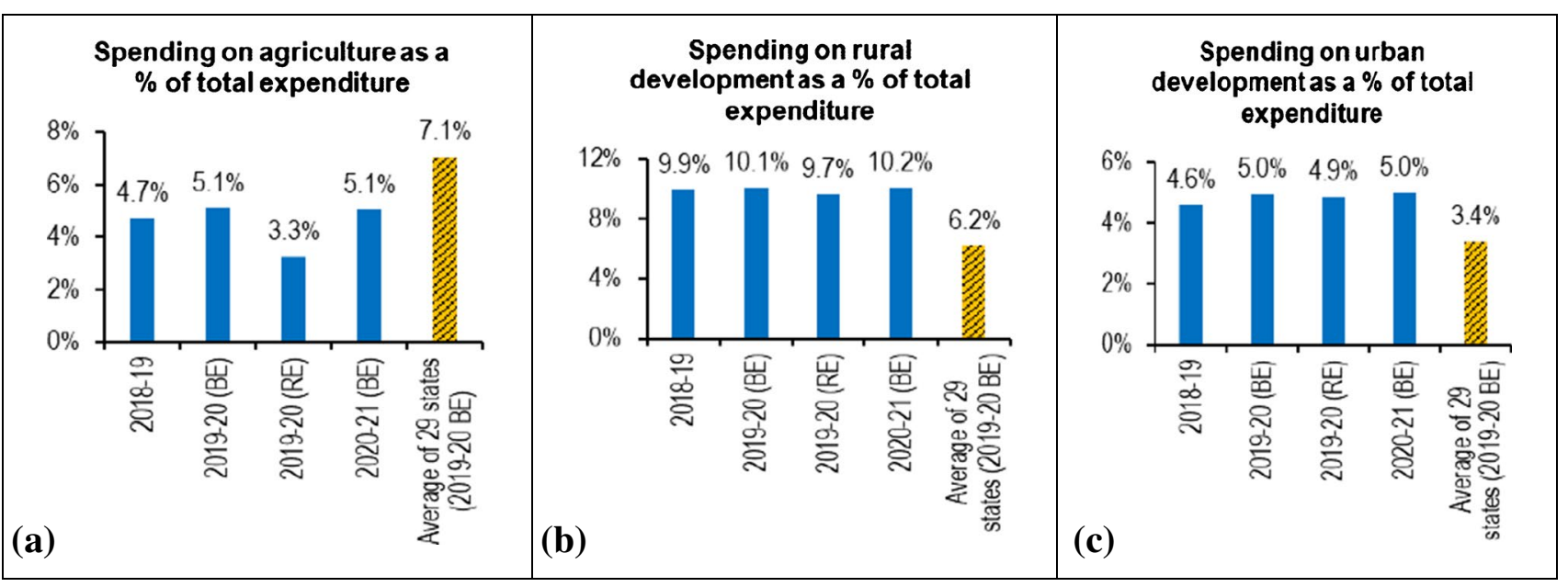

Fig. 8 Spending expenditure on a agriculture, b rural and c urban development sectors (sources: State Budget Documents 2019-2020 and 20202021 [Annual Financial Statement]; PRS). 
Fig. 9 a Programmes during the lockdown at university level. b Satisfaction level of university education system (source: Primary survey, May 2020-June 2020)

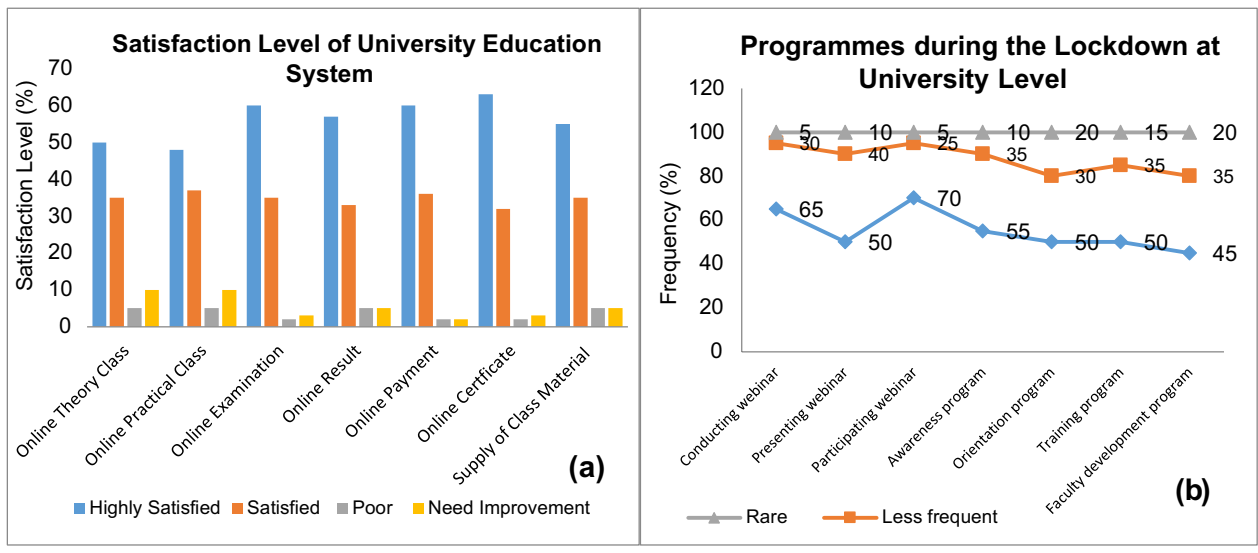

was quite high in North 24 Parganas (37\%), Howrah (29\%), South 24 Parganas (9\%), Hooghly (7\%) and moderate to low in Malda, Darjeeling, Uttar and Dakshin Dinajpur. Purba and Paschim Medinipur were found in a low zone in the rest of the districts.

The overall COVID-19 statistics of West Bengal (Fig. A10 in Appendix 1), as of August 16, 2020, revealed that the percentage of positive cases was $8.86 \%$; the mortality rate was only $2.08 \%$; the institutional quarantine rate was only $6.28 \%$, whereas the home quarantine rate was $92.72 \%$, and the recovery rate was quite high, that is, $74.48 \%$. These findings indicate that despite the increasing rate of active COVID-19 positive cases, the state can control the situation by increasing its recovery rate and decreasing the death rate.

Impact of COVID-19 on the economy COVID-19 has exposed a fault line in the global economic sectors; and developing countries, such as India, with a high-risk proneness and large population base, have suffered tremendously. The spread of COVID-19 continuously disrupts economic activity with a strong negative impact on manufacturing and service sectors, which will continue to increase in the near future and probably, the global economy is heading towards a disaster (Kanitkar 2020; Walter 2020). During the first 21 days of the complete lockdown in India, an estimated loss of US $\$ 4.5$ billion and approximately $53 \%$ of businesses were significantly affected. The agriculture and food sector contributes $43 \%$ to employment and $16.5 \%$ to GDP, which is the highest in India. The food processing sector, which deals with dairy, cereals and edible oil, was seriously affected. The export of agricultural products and fishing products from West Bengal to other parts of India were also evidently affected. The lack of industrial and financial investment in West Bengal's economy has already been doldrums for some time. All the economic sectors of Bengal starting from primary up to quandary sectors were severely affected by the lockdown and pandemic effects of the coronavirus. Henceforth, the state's economy was compared with other top states of India. The pillars of the economy of the state were also studied from diverse angles, such as GSDP, fiscal responsibility and budget management, sector-wise expenditure, import-export business and workplace mobility. Vegetables and perishable products also faced problems due to transportation in desired places, and people associated with it were struggling for existence due to the shortage of income. The fishing sector was trying to cope up with the situation with a huge loss. Even the online food grocery suffered a huge loss due to the restriction of the delivery
Fig. 10 a Satisfaction level of college education system. $\mathbf{b}$ Satisfaction level of the school education system (source: Primary survey, May 2020-June 2020)

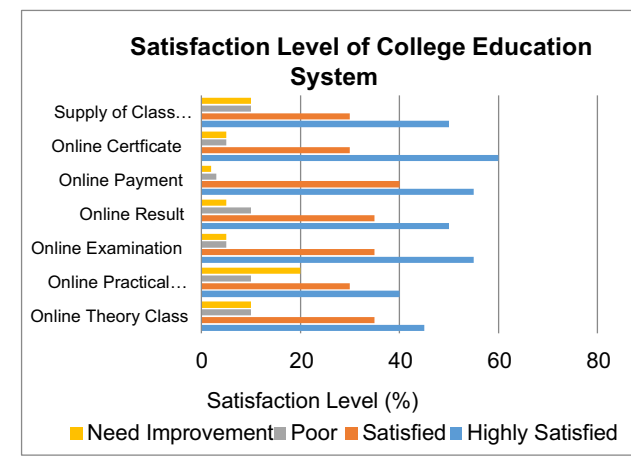

(a)

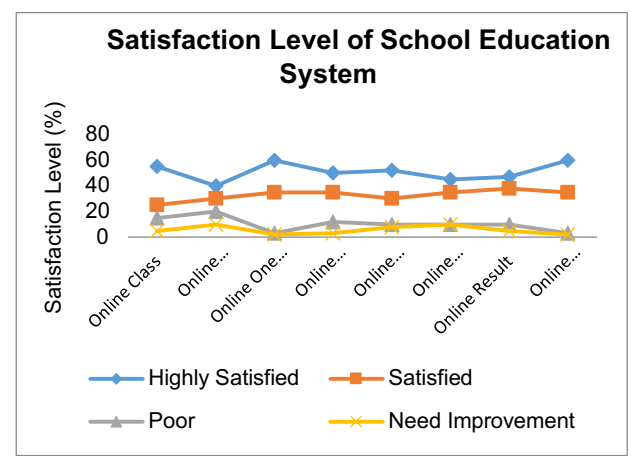

(b) 
system, especially during the prolonged lockdown in West Bengal. The online supply of household and personal care products, healthcare products, food and beverage sector, which contribute a good proportion to GDP and employment, showed a drastic fall. The micro, small, medium enterprises of rural and semi-urban areas, which contribute more than $30 \%$ in GDP, faced a sharp drop. Due to the breakdown of the supply chain as a result of the lockdown, the lack of production activity led to inflation. Although the situation got under controlled or normalised, the inflation would continue with a greater proportion.

The lockdown and social distancing hampered the production and supply of industrial essential products, and that affected the availability of some daily requirements of the livelihood of the state. During the lockdown, consumers showed a tendency to overstock essential commodities and products, such as rice, oil, lentils and grains, and it ultimately saw a fall in the stocks and disrupted the supply chain. Daily essentials showed a massive hike, but a drop occurred in lifestyle products. In this situation, the possible ways would not be found by slashing interest rates by the Reserve Bank of India or reducing taxes. According to an economist, a consolidated effort is needed to help the economy recover from the mess. The government should first stem the root by giving money to those who belong to unorganised sectors and associated with farming who do not have secure earnings.

West Bengal had a $24.87 \%$ share of primary sectors (India: $18.7 \%$ ), $14.93 \%$ of secondary sectors (India: 131.7\%) and $60.19 \%$ of tertiary sectors (India: $49.6 \%$ ) in the $2017-$ 2018 period.

The conditions of West Bengal's economy were compared with those of the other top five states in India. The study reveals that the top six states (Maharashtra, Tamil Nadu, Uttar Pradesh, Karnataka, Gujarat and West Bengal) make up almost half of India's economic output (Fig. 4). Google data reveal that in September 2020, workplaces in these states recorded $69 \%$ of their normal footfalls, and this percentage is the highest since the lockdown began in March 2020. The rest of India recorded $78 \%$ of the normal footfalls at workplaces, the worst level since May 2020, as cases spread faster in smaller states. In 2020, the case load share of the top six states of India (including West Bengal) reduced to $47.2 \%$ in October 2020 from $60 \%$ in April 2020, whereas the national proportion was increased to $52.8 \%$ from $40 \%$ in the same period.

Workplace mobility is one of the high-frequency indicators in the recovery tracker. Small-sized state economies in the tracker saw the greatest drop in workplace mobility-from 83 of normal footfalls in August 2020 to $72 \%$ in December 2020. During September 2020, mobility at other public places, such as recreation spots, parks and shops, was unavailable. The proportion of mobility ranged from -45 to
$-5.7 \%$ in India; meanwhile, the top six states ranged from -60 to $-20.6 \%$ from April 2020 to October 2020, which has a strong impact on the economic sloth. The electricity use of the top six states increased from -25 to $10.7 \%$ in comparison to the national increase of -25 to $13.4 \%$ from April 2020 to October 2020.

Three other indicators, which serve as proxies for economic activity-electricity consumption, goods and services tax collections, and vehicle sales-are also considered in the tracker. Approximately 1.34 million new vehicles were registered in September 2020, $11 \%$ lower than year-ago numbers, but the highest in six months showed data from the road transport ministry. The top six states performed slightly better (10\% drop) than the rest of India (12\%). Several states even exceeded the year-ago numbers; on average, mediumsized states and small-sized ones were $18 \%$ and $6 \%$ behind the year-ago vehicle registration numbers, respectively.

On the basis of the GSDP growth rate of $11.3 \%$ over the previous year (2019-2020), the (GSDP) of West Bengal for 2020-2021 (at current prices) was estimated to be RS₹ $14,44,1.74$ billion. It was estimated to grow at a $14.6 \%$ rate in 2019-2020 compared with the $7.5 \%$ growth rate estimated for India's GDP.

In 2019-2020, agriculture, manufacturing and services were estimated to contribute $21 \%, 20 \%$ and $59 \%$ to the state's economy, respectively. Major sectors, such as agriculture (66\%); irrigation and flood control (39\%); and welfare of SC, ST, OBC and Minorities (38\%) saw the highest increase in allocations. Meanwhile, allocations to sectors such as transport (21\%), social welfare and nutrition (19\%) and police (6\%) saw the highest decrease (Fig. 5a).

Major items exported from West Bengal are iron, steel, gold and other precious metals. The total exports of iron and steel from West Bengal in 2018-2019 stood at US\$ 1,040.49 million, which was $10.49 \%$ of the total exports (Fig. 5b).

The West Bengal Fiscal Responsibility and Budget Management (FRBM) Act 2010 provides annual targets to reduce the outstanding debt, fiscal deficit and revenue deficit of the state government progressively, which are targeted in its budget even after the COVID-19 outbreak and related issues (Fig. 6a). The budget estimates a zero-revenue deficit (excess of revenue expenditure over revenue receipts) in 2020-2021. It implies that revenue receipts are expected to be the same as revenue expenditure. In 2020-2021, the fiscal deficit (excess of total expenditure over total receipts) is estimated to be Rs₹ 31,4830 million, which is $2.18 \%$ of GSDP. In 2019-2020, the fiscal deficit was estimated to $2.63 \%$ of GSDP compared with the budgeted estimate of $2.1 \%$ of GSDP.

Moreover, the outstanding debt is the accumulation of borrowings taken by the state government over the years. In 2020-2021, the state's outstanding debt is expected to be $32.9 \%$ of the GSDP (Fig. 6b). This estimate is much higher 
than the limit of $20 \%$ of GDP suggested by the FRBM Review Committee (2017) for the cumulative debt of all states. In 2020-2021, West Bengal is expected to spend Rs₹ 77, 0470 million on servicing its debt. This amount is 5.5\% lower than the revised estimate in 2019-2020. It includes Rs₹ 44,2890 million towards repaying loans and Rs₹ 32,7580 million towards interest payments.

The sector-wise expenditure of the 2020-2021 budget of West Bengal is tabulated to observe the changes over the last budget year (Fig. 7). From the 2019-2020 to the 2020-2021 budget allocation figure, the education and rural development sectors had $12.3 \%$ positive changes; the health and family welfare sector had $6.8 \%$ changes; agriculture and allied activities had $65.9 \%$ changes; urban development had $10.2 \%$ changes; some other sectors, such as social welfare and nutrition, had a negative change of $19.4 \%$; the transport sector had $-21.2 \%$; the police sector had $-6.4 \%$ changes.

Fig. 8 shows the comparison result of West Bengal's expenditure on six key sectors as a proportion of its total expenditure on all sectors. The average for a sector indicates the average expenditure in that sector by 29 states of India.

The state has allocated $5.1 \%$ of its expenditure towards agriculture and allied activities in 2020-2021, and that is much lower than the average allocation by states (7.1\%). West Bengal has also allocated $10.2 \%$ of its expenditure for rural development in 2020-2021 that is significantly higher than the average allocation for rural development by states (6.2\%). In addition, West Bengal has allocated 5\% of its expenditure for urban development in 2020-2021, which is higher than the average allocation for urban development by states $(3.4 \%)$.

Impact of COVID-19 on employment Based on the MRD (Merchant Discount Rates) report, a job loss of 40 million people in India is evident, mostly in unorganised sectors. Thus, after analysing the COVID-19 impact on the economy, the employment sector was investigated in the present study to understand the employment loss and mobility of the people associated with unorganised sectors. These sectors and semi-skilled job holders lose their employment, and such a situation is another kind of pandemic to daily wage earners due to the outbreak of COVID-19 (Kapasia et al. 2020). The Mahatma Gandhi National Rural Employment Guarantee Act schemes were affected the most. They could not provide any jobs due to the lockdown in India, and the scenario in West Bengal is not an exception. A huge number of employees were losing their jobs, mostly in private and informal sectors. A large amount of unprecedented wage labour in the construction sites and farms in West Bengal working in other states, such as Kerala, Tamil Nadu and Rajasthan, returned home to West Bengal. Employment opportunities in formal and informal sectors and government and private sectors have reduced due to the pandemic. Even the work-from-home environment cannot fulfil the desires of job-giving companies, co-sequencing a large number of laid-off employees and an acerbic reduction of salaries for some existing employees.

According to the Periodic Labour Force Survey (20172018), the unemployment rate in West Bengal is $4.6 \%$, which is lower than the all-India unemployment rate of $6.1 \%$. This situation became worse during the lockdown, as most laborers left their jobs or got fired by their employers.

Impact of COVID-19 on education Due to the sudden outbreak of COVID-19, the face-to-face and/or conventional education system worldwide has been stopped and has inclined to blend online learning and find alternatives. From nursery kids to school-going children up to the students and scholars of the higher education system are learning via online mode. Even certain examinations are conducted online. In this backdrop, the complete shutdown of all the educational institutions for an uncertain period was observed when situations in West Bengal were analysed. This condition was seen in most of the other parts of the state and in the whole country. The educational system is trying to develop a new strategic approach or model of blended learning of diverse disciplines to cope up with the situation in the post-COVID-19 era. COVID-19 has completely affected the education system (Kumaran et al. 2020). The present study concentrates on information and communication technology (ICT) usage, e-focus and e-enhancement, supported online modes, supplemental study materials, buffet materials and methods that can be encouraged by conventional institutions' future delivery mechanisms.

Despite the current popularity of blended learning in developed countries, it is less used in educational institutions in India. Blended learning has become an utmost priority throughout the country. The traditional face-to-face learning of conventional institutions is becoming a challenge. Therefore, new models or approaches are needed in the higher education system for their practice-based and non-practical discourses. Thereafter, a newly planned, pedagogically valuable, ICT-supported blended mode, which can be accepted by institutions across the country and probably across the world, is an urgent need. Practical-based subjects are challenging, and institutions are spreading education in a way that has shifted the paradigm from a conventional teachercentric to a non-conventional learner-centric system, with the application of Internet communication.

The fraternity associated with the education sector conduct, present and participate in online webinars on the diverse topics related to their discipline or current scenarios or awareness, orientation programmes, training programmes and faculty development programmes. Almost all these programmes are fruitful in their purpose and create awareness and strengthen their strategies to fight against this 
virus. However, the over-dependency on electronic media or mobile phones for that purpose is generating some extra burden and anxiety in their daily life and livelihood. Students, especially those below 20 years of age, are becoming addictive and vulnerable due to the overuse of electronic gadgets for their educational purposes. Sometimes, these gadgets can no longer meet their actual purpose, and a co-sequencing arrogant behaviour is observed.

The online survey conducted in May 2020-June 2020 regarding the impact assessment of lockdown and COVID19 pandemic on school education and the higher education system of UG and PG of five universities of West Bengal revealed that online teaching-learning mode is the only option for the educational fraternity. However, stakeholders face various challenges during this online teaching-learning process. Teachers and learners face difficulties. Nevertheless, they are quite satisfied with the situation in certain cases.

All the surveyed universities frequently conducted online webinars $(65 \%)$, awareness programmes (55\%), orientation programmes (50\%), faculty development programmes (45\%) and training programmes (50\%). The concerned faculties duly participated and presented (frequency level of more than 50\%) in these programmes (Fig. 9a). The students of PG course of the various disciplines in universities were highly satisfied with the online theory and practical classes (> 80\%); online examination and result publication (> 85\%); online certificate, payment options ( $>90 \%)$ and supply of study material (> 85\%) (Fig. 9b).

The students of UG courses of the various disciplines in colleges were highly satisfied with the online theory and practical classes (> 70\%); online examination and result publication ( $>80 \%)$; online certificate, payment options (> $90 \%$ ) and supply of study material (> 80\%) (Fig. 10a).

School-going children face proportionately high difficulties during their online studies. The survey revealed that they are satisfied with the online classes $(>80 \%)$; online examination and result publication ( $>80 \%)$; payment options (> $90 \%)$, online report card (80\%), one-to-one interaction and parent-teacher meet $(>80 \%)$ but comparatively less satisfied with the online school activities (> 70\%) (Fig. 10b).

The survey also portrayed the challenges and difficulties faced by the stakeholders of the education system, especially the students (Fig. 11). The graph reveals that most respondents (teachers and students) face difficulties $(>55 \%)$ regarding Internet network and communication, new mobile app usage, voice break problem and video pause issue during class, technological challenges, lack of IT support and comfortableness and security issue; meanwhile, students complain (> 60\%) about the lack of supporting study material, lack of preparedness and time boundedness, whereas teachers are worried (> 60\%) about maintaining class discipline and the mobile addiction of students.

The graphs below (Fig. 12) compare West Bengal's expenditure on the education sector as a proportion of its total expenditure on all sectors. The average for a sector indicates the average expenditure in that sector by 29 states

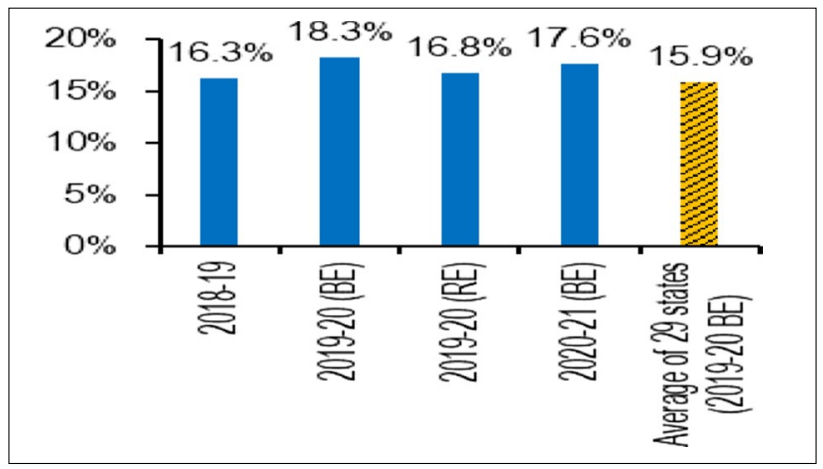

Fig. 12 Spending expenditure on the education sector (sources: State Budget Documents 2019-2020 and 2020-2021 [Annual Financial Statement]; PRS)
Fig. 11 Challenges faced by the online education system ( Source: Primary survey, May 2020-June 2020)

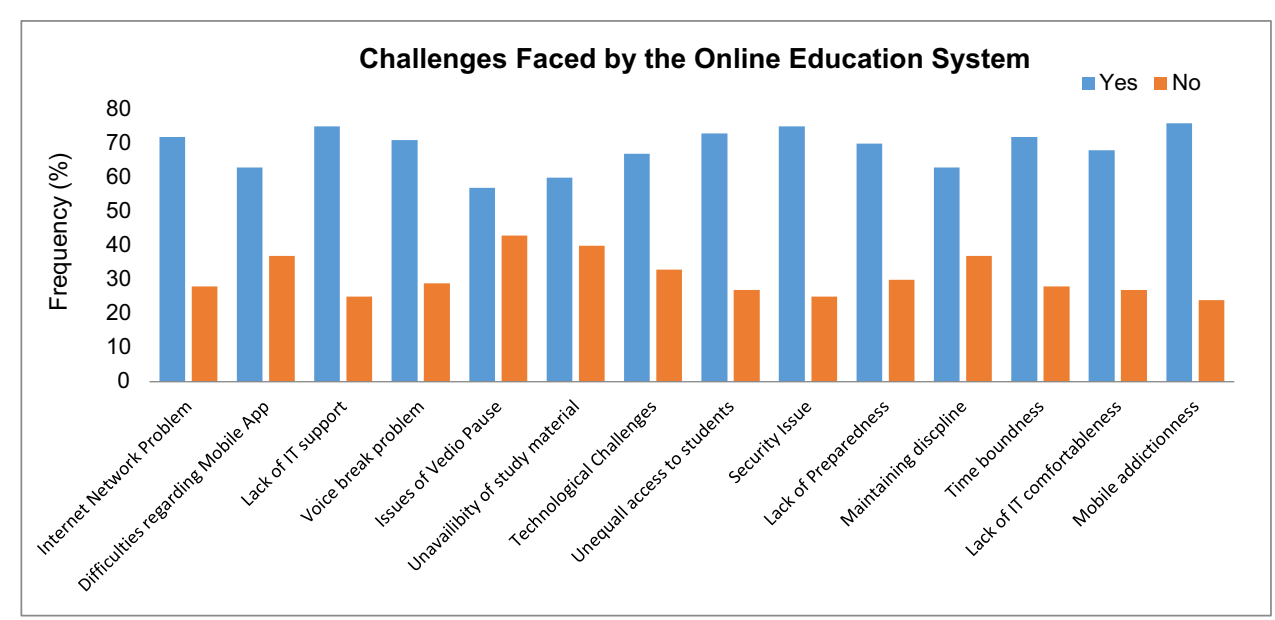


of India. West Bengal has allocated $17.6 \%$ of its expenditure for education in 2020-2021, which is higher than the average expenditure (15.9\%) allocated for education by states (using 2019-2020 BE).

Impact of COVID-19 on transport The population growth rate is quite high in West Bengal. Therefore, its transportation system has been affected due to the pandemic and lockdown. The population density is very high in West Bengal (Fig. A11 in Appendix 1); thus, most travellers and commuters must avail public transport systems. The diverse modes of public transport, such as local train, metro railway, bus, tram and auto, are quite risky for travelling during a pandemic situation where social distancing is the mantra to control the outbreak and spread of COVID-19. Taxi, ola and uber-like cab transport cannot provide the required services, and the prices of such services are beyond the limit of most people in this money-shortage period. The government of West Bengal is trying to adjust the situation by providing some bus services for emergency purposes to remain open to some essential sectors, such as hospital, police and administration. The number of such services is insufficient, and travelling by any mode of transport generates additional active COVID-19 positive cases (Abdullah et al. 2020).

The transport system became severely affected due to the complete lockdown in the state. With the associated stakeholders losing their jobs, the income of the government from this sector was reaching the bottom. Thereafter, West Bengal has allocated $2.3 \%$ of its expenditure for roads and bridges in 2020-2021, which is much lower than the average allocation for roads and bridges by other states $(4.2 \%)$ of India (Fig. 13). For this reason, the affected damages in this sector have not recovered properly.

Impact of COVID-19 on travel and tourism Due to the sudden outbreak of COVID-19 worldwide, the travel and tourism sector has been drastically breaking down and looking for alternatives (Abu-Rayash and Dincer 2020; Beck and

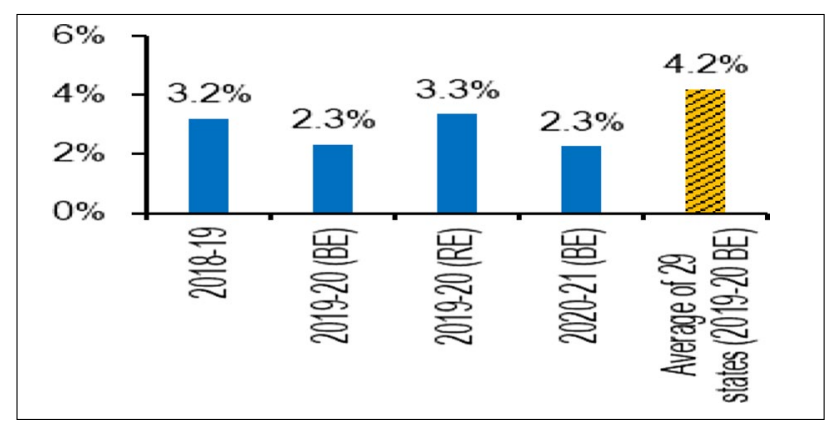

Fig. 13 Spending expenditure on roads and bridges (sources: State Budget Documents 2019-2020 and 2020-2021 [Annual Financial Statement]; PRS)
Hensher 2020; Sigala 2020). In the lockdown phase, where the country borders are sealed and international communication by any physical mode or transport mode is postponed, creating numerous challenges for the travel and tourism sector consequences pathetic conditions of the economy worldwide, especially in developing countries (Uğur and Akbıyık 2020; Kreiner and Ram 2020). Even after getting the situation under control, people will be scared to travel to places in the new normal period. Thus, this sector must be boosted up by a new strategic approach or model to cope up with the situation in the post-COVID-19 era (Barman et al. 2020). With the combination of government and private sectors, along with the application of an improved management system, this sector should plan their prospect worldwide. Thus, the present research attempts to record extensive case studies and analyses the COVID-19 impact, vulnerability, challenges and prospects in the travel and tourism sector. The study also aims to find alternative approaches or models to adopt to the situation. This sector may concentrate on the ICT usage, e-focus, future delivery mechanism, and the outcomes from the statistical analysis of travel and tourism in the pandemic situation can be used as a basis to find alternative and probable encouraging views. Thus, the various aspects of travel and tourism are focussed in the work, so that the outcomes will be enormous and purposive, and thus will make a difference in the real scenario. Doing so will definitely shed some light on the diverse issues regarding travel and tourism development and its economic and societal aftermath in the new normal phase of the postCOVID-19 era and will thus become a landmark.

In the pre-COVID era in 2019, India attracted 10.5 million foreign visitors; five million non-resident Indian travelled back home to be with family and friends; 1.8 billion Indians travelled within the country for holidays, pleasure and leisure; 26 million Indians travelled overseas for tourism. Moreover, India has an estimated 53,000 travel agents, 115,000 tour operators, 15,000 adventure companies, 911,000 tourist transporters, 53,000 hospitality companies and five lakh restaurants. This industrial sector employs an estimated 38 million people. All of these statistics seem like a far cry today, and on current indications, the lockdowns and curfews may continue until the start of the coming year in varying intensities and impositions. A significant proportion of companies are actively seeking to reduce business travel and to cut the number of employees commuting even to the workplace.

West Bengal is generally known as a diverse state in terms of its tourism sector, as the state has many places to visit that attract a large volume of domestic, national and international tourists almost throughout the year. As per the telephonic interview with some known travel agents, tour operators and tourists, we find that all of them are facing 
difficulties and challenges due to the sudden lockdown in the country (Fig. 14). The associated stakeholders are facing less income as their monetary investment in the sector is locked ( $>55 \%$ ), and some of them are bound to look for alternative income generation ( $>55 \%)$. Tourists are getting trapped (45\%) at home for safety reason, and some of them have problems regarding their reimbursement of paid money for travel purposes $(>70 \%)$. Some hotel owners and tour operators have closed their business $(>40 \%)$ and suffered from an extreme economic crisis ( $>60 \%)$. Most stakeholders in these sectors are worried about their future. India is becoming an increasingly large group travel market for firsttimers and middle-class families. In this pandemic situation, no one knows when the fury of the virus will abate; people are cloistered in their homes; social distancing is becoming the new mantra; masks and gloves are the new safety accoutrements; no one is even thinking of a holiday. Thus, leisure travel will also dwindle for some time; global travel seems bleak, and therefore, domestic prospects may be somewhat better. Tourism may look inwards, be more domestically directed and in the future, 'capability' 'capability', which will have concentrated on the 'cope up ability' or 'the ability to adjust without hampering the willingness of travel' or 'amend with the travel for working purpose' even in the epidemic or pandemic situation. The pickup of the travel and tourism industry is the farthest in that chain, as it is inextricably linked to the return of normalcy, that too soonest. Until then, travel and tourism are literally in the doghouse during the COVID-19 pandemic. People in the industry will work hard to cope with change and the new normal; some will succeed, some will struggle, and some will perish.

Impact of COVID-19 on health Heath emergencies around the globe arose after the declaration of the WHO due to the pandemic infection of the novel coronavirus. The impact of the virus started exhibiting in Indian states in March 2020

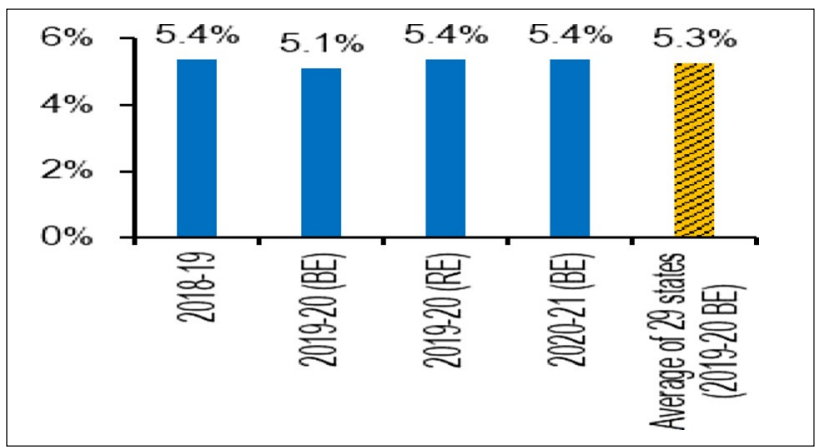

Fig. 15 Spending expenditure in the health sector (sources: State Budget Documents 2019-2020 and 2020-2021 [Annual financial statement]; PRS)

(Shehzad et al. 2020). On March 26, 2020, a committee of experts was constituted by the Government of West Bengal to advise the health situation and suggest strategies for isolation, quarantine, testing, COVID-19 prevention and building health infrastructure. Various monitoring committees managing clinical care, isolation wards, judging the cause of death and handling related issues are important. Government healthcare facilities are becoming insufficient and thereafter, private sectors were acquired in April 2020 in response to the increasing number of positive COVID-19 cases. The government also issued several guidelines and orders on patient handling, virus containment, protection of healthcare workers along with the lockdown rules and regulations. Hot spots and contaminated zones were classified into red, orange and green zones. Moreover, guidelines for the treatment and lockdown strategies in those areas are continuously monitored. Furthermore, the government created relief funds and distributed food. Some measures were taken for the workers (e.g. doctors and nurses) in the health sectors; free insurance was also introduced.
Fig. 14 Challenges faced in the travel and tourism sector ( source: Telephonic survey, October 2020)

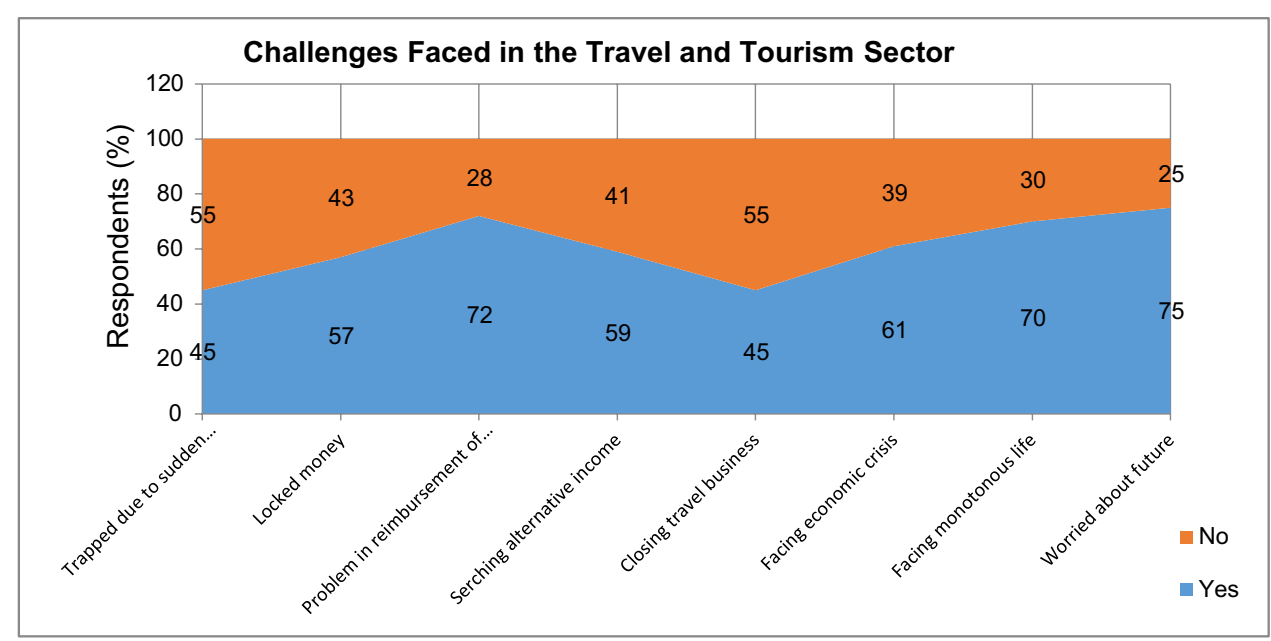


The graph in Fig. 15 compares West Bengal's expenditure on the health sector as a proportion of its total expenditure on all sectors where the average for a sector indicates the average expenditure in that sector by 29 states of India. West Bengal has allocated $5.4 \%$ of its expenditure for health in 2020-2021, which is marginally higher than the average allocation for health by states (5.3\%). Still, netizens are panicking about physical and mental health disorders and related health hazards. Many motivational programmes have been conducted by different educational institutions, governments, private sectors and non-governmental organisations all over India to improve awareness, promote yoga, improve people's health and cater health hazards; some of them are found effective, especially for elderlies, as observed by the authors.

Impact of COVID-19 on the environment The impact of COVID-19 on the environment is multidimensional and global. Finding a clean environment that is in good condition, which has never existed in this century yet, is somewhat better; this occurrence is the ray of hope in the agony of pain. The spatial scale may be different, but the impact is huge, and its level is significant. The diverse environmental components are taking a large break from their continuous exploitation and exploration related to human activities. They can also breathe properly in a new form, which can be a blessing for nature and the environment. Thus, improving climatic conditions to decrease pollution rates and to perfect air quality is the pillar and hope amidst the negative effects of COVID-19 worldwide (Acharya and Porwal 2020). India is dealing with population pressure, and developing countries are facing the situation in wide ranges (Ranjan et al. 2020). Approximately $12.5 \%$ of all deaths in India are responsible or associated with air pollution stated in the State of India's Environment Report. The air quality and water quality of West Bengal, especially in the industrial and urbanised areas, have started to improve from the start of the lockdown. This improvement is evident from the comparative assessment of the pre- and post-lockdown periods.

The comparative assessment of nitrogen dioxide $\left(\mathrm{NO}_{2}\right)$ concentrations and sulphur dioxide $\left(\mathrm{SO}_{2}\right)$ concentrations before and after the lockdown in West Bengal, including the surroundings, was performed minutely in this research, revealing an improvement in the environment (Figs. 16 and 17).

The pollution levels of these two important elements were reduced at significant levels, which indicate the good condition of the environment; less pollution and environmental degradation were also observed ( $\mathrm{Li}$ and Tartarini 2020; Chowdhuri et al. 2020). From the comparison of the improvement of environmental conditions in the case of $\mathrm{NO}_{2}$ from January 1, 2020, to April 20, 2019 (before the lockdown), and from January 1, 2020, to April 20, 2020 (after lockdown), the middle and western parts of the state became clear, and low $\mathrm{NO}_{2}$ concentration was observed.
Fig. $16 \mathrm{NO}_{2}$ concentrations before and after the lockdown in West Bengal ( source: https:// www.esa.int)

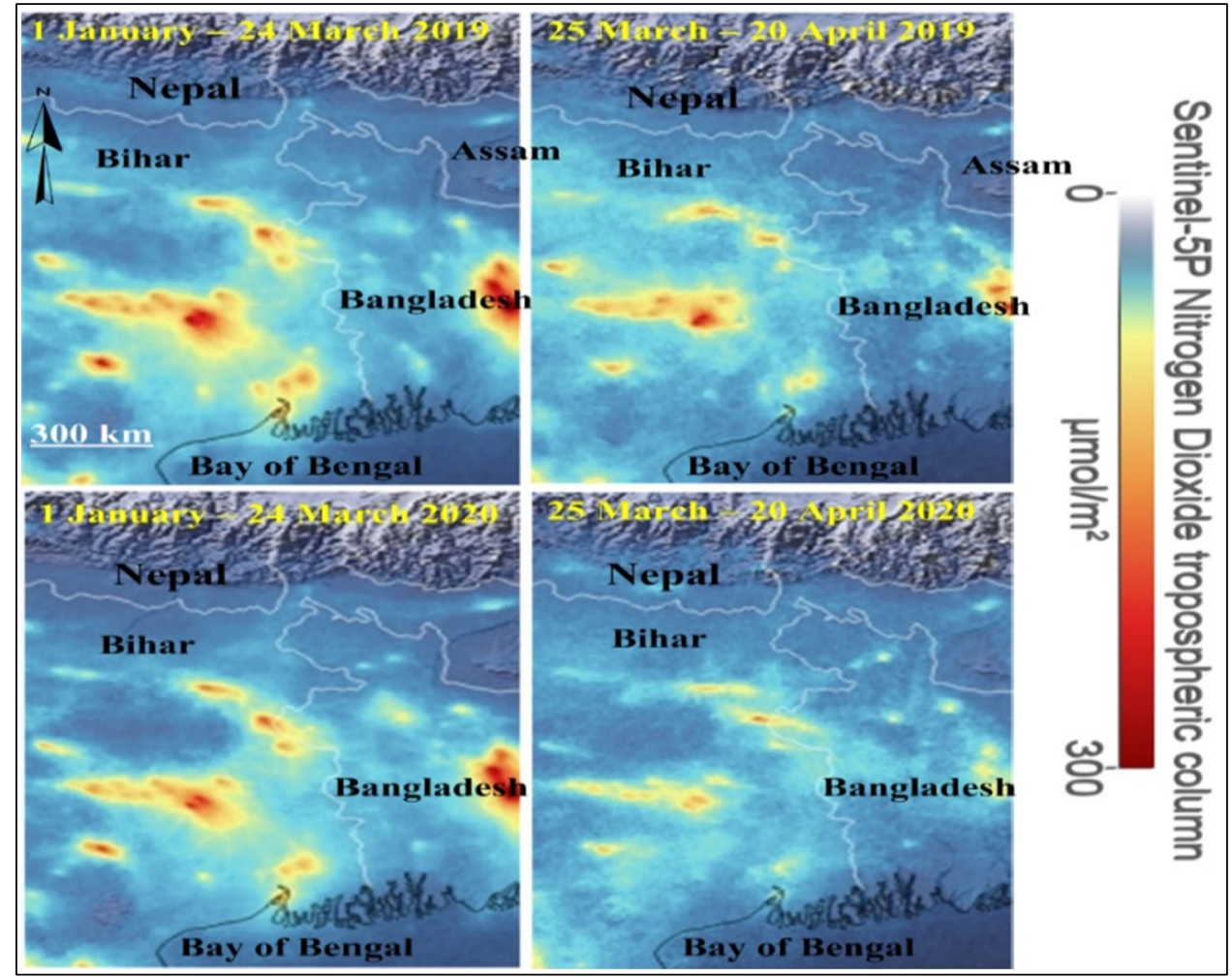


Fig. $17 \mathrm{SO}_{2}$ concentrations of before and after the lockdown in West Bengal ( source: https:// www.esa.int)

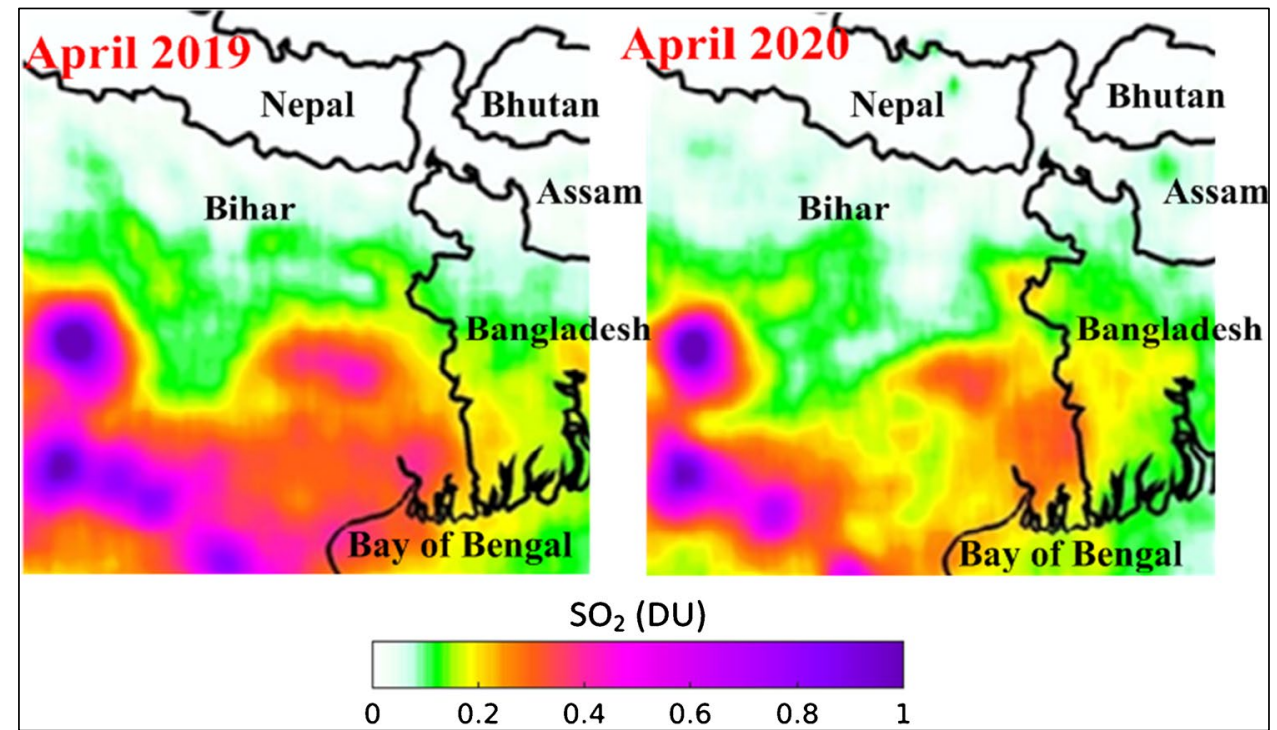

The SO2 level was reduced from 1 DU to $0.4 \mathrm{DU}$ or less from April 2019 to April 2020 in most states and their surroundings. The $\mathrm{NO}_{2}$ concentration was also significantly reduced from $300 \mathrm{umol} / \mathrm{m}^{2}$ from January 2019 to April 2019 to a very negligible condition from January 2020 to March 2020. The concentration was found almost nil in April 2020.

Another observation was that the vegetation cover, especially in the urban areas, was increased and became eyesoothing due to the non-disturbance and reduced pollution level during the lockdown period (Sarkar et al. 2020). The vegetation cover improvement of some major urban parts of West Bengal, such as Kolkata, Siliguri, Durgapur, Asansol and Haldia, was a portrait of the years 2019 and 2020 to observe how muck the environmental progress in the case of vegetation cover was achieved during the lockdown (Fig. 18 and Fig. A12 in Appendix 1).

\section{Spatial analysis and correlation}

The spatial analysis of the districts of West Bengal was conducted using different relevant statistical and geospatial techniques where we attempted to correlate the selected seven sectors and analyse the impact of COVID-19 by taking some relevant indicators related to the current study. The statistical analysis by standard score, location quotient, composite score and gravity model helped investigate the impact of COVID-19 cases district-wise. A significant connection amongst the variables was also observed in the study.

The correlations amongst the selected sectors, including their allied categories, their relevancy, associated districts and the nature of the impact of COVID-19, were observed, analysed in the current study and tabulated (Table 1).

Taking some of the selected indicators related to the current study, some statistical analyses were accomplished,
Fig. 18 Urban vegetation changes between 2019 and 2020 for Kolkata
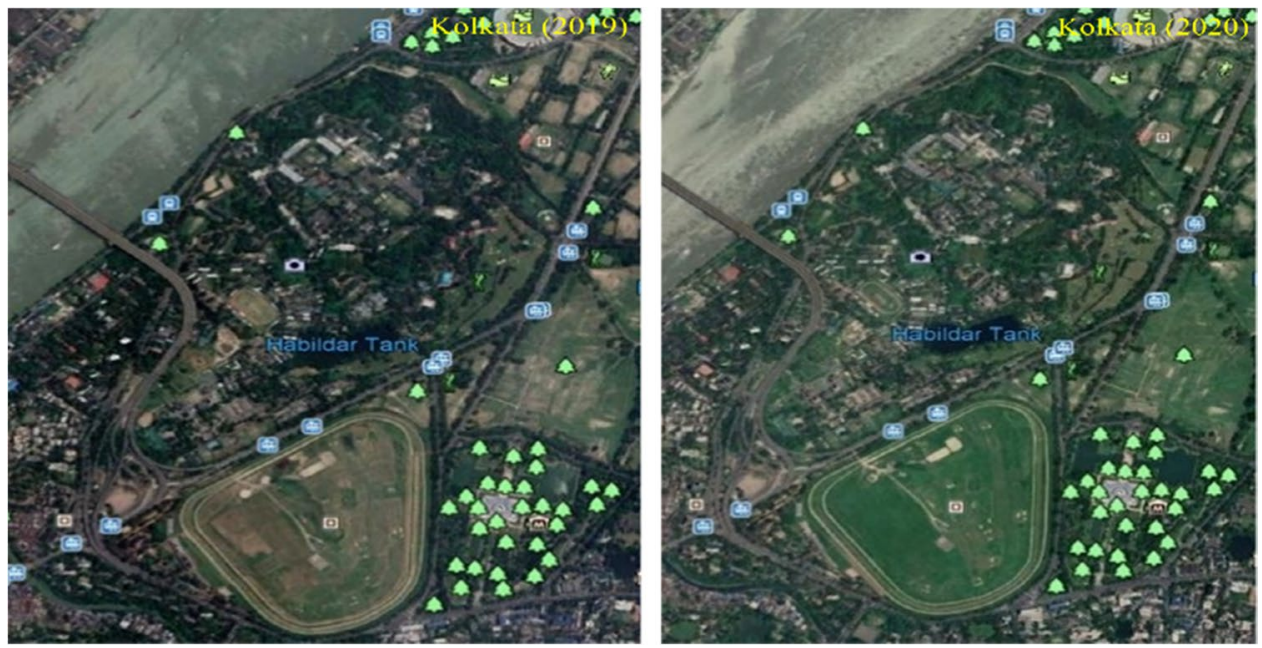


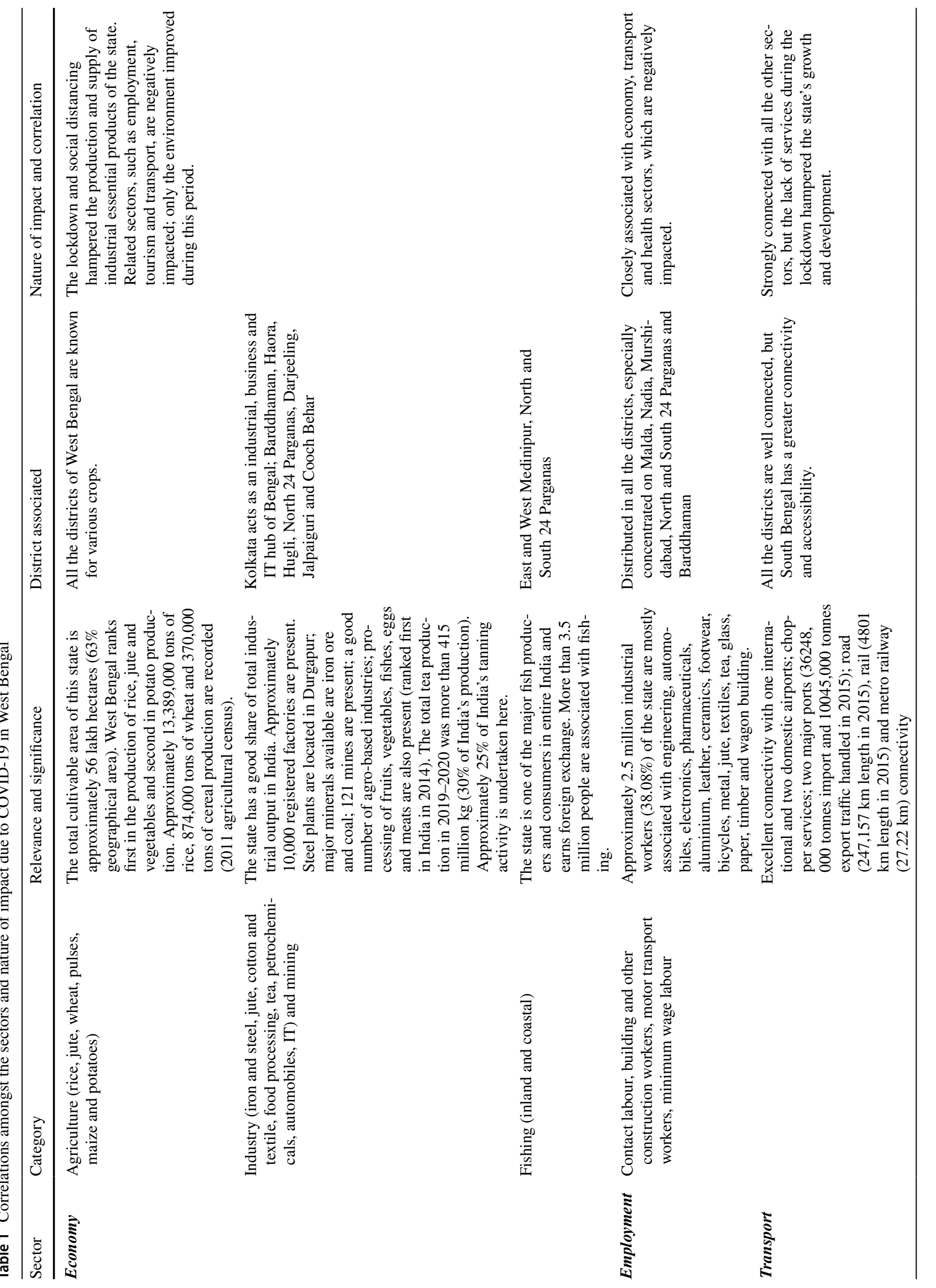




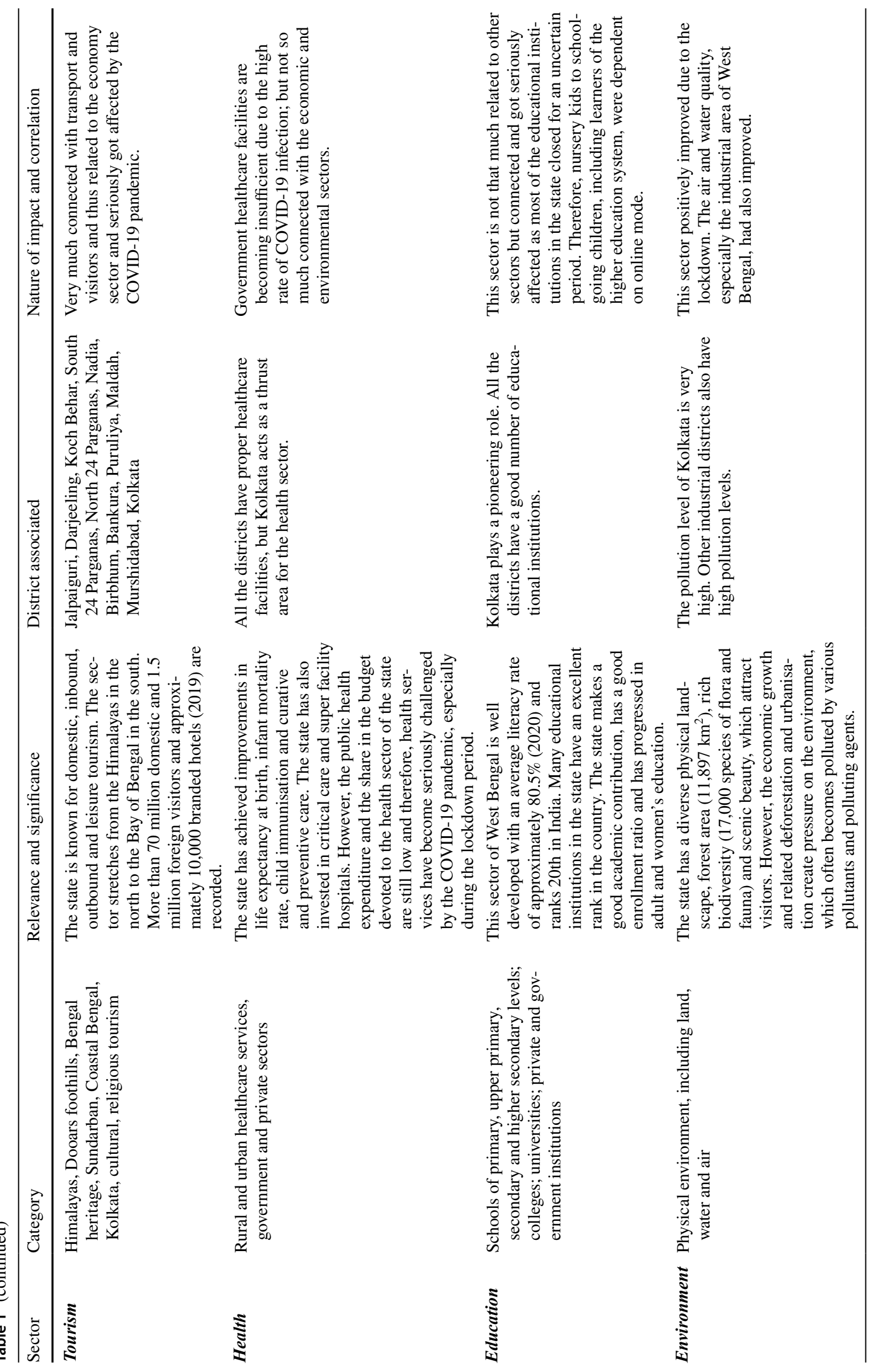


resulting in 10 categories, such as population characteristics (population growth, population density, sex ratio and percentage of urban population to total population), education (female literacy rate, rural literacy rate, number of primary schools per lakh of population, number of high and higher secondary schools per lakh of population, number of colleges per lakh of population and number of students per school), employment opportunities (male employment rate, percentage of workers engaged in cultivation, percentage of workers engaged in agriculture labour and percentage of workers engaged in other works), health and medical facilities (number of hospitals and primary health centres per 0.1 million of population and number of beds in hospitals per 0.1 million of population), agriculture (concentration of agricultural labour and cultivator), industry (number of registered factories per $100 \mathrm{~km}^{2}$ of area), infrastructural facilities (percentage of electrified village to total villages and number of motor vehicles on road per 0.1 million of population), transport and communication, per capita income and banking facilities. The standard score or Z-score value of all the variables was calculated, added and averaged to express the composite score for each district. A large range of variations in the score amongst the districts of the state was observed, where the lowest score $(-0.30)$ and the highest score (0.46) were found in Murshidabad and in Kolkata, respectively. The values were grouped into three categories and tabulated below.

Table 2 depicts that the high level (above 0.15 ) of development is witnessed only in three districts of the state, namely, Kolkata (0.46), Hugli (0.21) and Darjeeling (0.17); the medium category (from 0.15 to -0.15 ) of development is found in 11 districts of the state, namely, Birbhum (-0.04), Barddhaman (0.06), Nadia (0.07), North 24 Parganas (0.06), Bankura (0.12), Howrah (0.06), Jalpaiguri (-0.02), Cooch Behar (0.10), Dakshin Dinajpur (0.12), East and West Medinipur (0.13); the low level (below -0.15) is found in five districts of the state, which are Uttar Dinajpur $(-0.30)$, Malda (-0.16), Murshidabad (-0.31), South 24 Parganas $(-0.18)$ and Purulia $(-0.20)$. Thus, the composite score of Z-score values of socioeconomic indicators displayed that the high or medium level of development is found mostly in the southern and slightly in the northern districts, whereas the districts having low levels of development form a linear region in the central part of the state. It indicates that high levels of industrial, infrastructural, urban development, educational and health facilities are more concentrated in the southern districts than in the central and northern districts of the state.

The spatial analysis of the concentration of road network and road density, levels of development and their relationship obviously reveals a wide range of variations amongst the districts of the state. The spatial patterns of road density (Fig. 19) show that the level of road density is either high or medium in most districts of West Bengal, excluding Cooch Behar and Uttar Dinajpur in the north and Bankura in the eastern part of the state where the road density is low. The level of development is high or medium in the southern and northern districts of the state, whereas the level of development is low in central districts. However, the relationship between road density and level of development discloses that approximately $60 \%$ of districts of the state have a perfectly positive relationship, and the remaining districts of the state are moderately associated in terms of road density and level of development. To observe the impact of COVID-19 on the structure of development, a zone of influence using the gravity model from Kolkata (as it serves as the hub and centre of development and is mostly affected and threatened by COVID-19) was calculated and graphed (Fig. 19). It depicts that most districts, which have short-to-medium distance and dense population and are mainly concentrated in the southern region, are largely influenced by the COVID19 pandemic; meanwhile, the northern districts located far from Kolkata are comparatively less affected.

When we considered the percentage of each indicator of the districts and added the percentage of COVID-19 cases (taken the data recorded on January 15, 2021) to the existing value, we obtained a different result. In this statistical analysis, we calculated the percentage deviation of each district figure from their respective state-level figure, and then used the midpoint score calculation formula to determine the final score. It shows that Kolkata has the highest value, whereas Uttar Dinajpur has the lowest value. On the basis of the final score, all the districts were categorised into five groups and tabulated.

The tabulated value (Table 3) signifies that Kolkata, North 24 Parganas, Hooghly, Howrah, Barddhaman and

Table 2 Levels of development by Z-score

\begin{tabular}{lllll}
\hline Category & Z-score & $\begin{array}{l}\text { No. of } \\
\text { districts }\end{array}$ & $\begin{array}{l}\text { Percentage of } \\
\text { total districts }\end{array}$ & District \\
\hline High & Above 0.15 & 4 & 22.22 & $\begin{array}{l}\text { Kolkata, Hooghly and Darjeeling } \\
\text { Jalpaiguri, Cooch Behar, Dakshin Dinajpur, Birbhum, Barddhaman, } \\
\text { Medium }\end{array}$ \\
& From 0.15 to -0.15 & 9 & 50.00 & $\begin{array}{c}\text { Nadia, North 24 Parganas, Bankura and Howrah, East Medinipur and } \\
\text { West Medinipur }\end{array}$ \\
& Below -0.15 & 5 & 27.78 & Uttar Dinajpur, Malda, Murshidabad, South 24 Parganas and Purulia \\
\hline
\end{tabular}




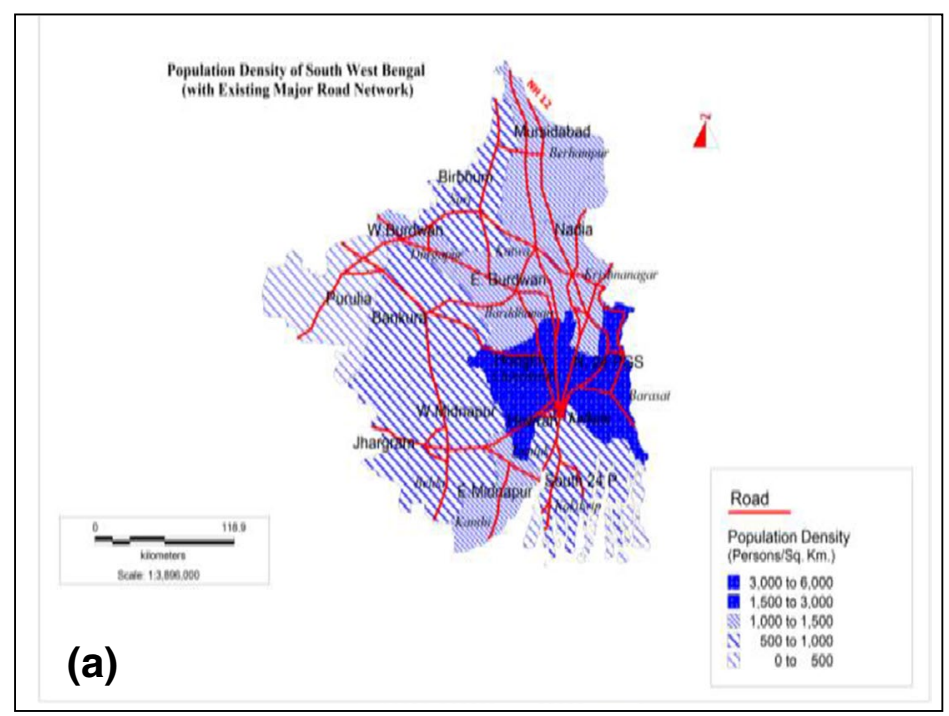

\section{Zone of Influence of the Districts of West Bengal from Kolkata}

$\longrightarrow$ Distance from Kolkata (km.) $\longrightarrow$ Gravity value

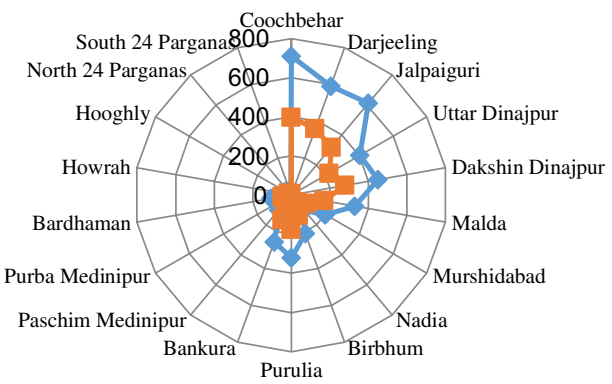

(b)

Fig. 19 a Population density and road network of South Bengal. b Zone of influence of the districts of Kolkata

Table 3 Levels of development and COVID-19 cases in the districts of West Bengal

\begin{tabular}{lllll}
\hline Category & Residual & No. of districts & $\begin{array}{l}\text { Percentage of total } \\
\text { districts }\end{array}$ & District \\
\hline Very high & Above 65 & 2 & 10.52 & Kolkata and North 24 Parganas \\
High & $60-65$ & 1 & 5.26 & Hooghly \\
Medium & $55-60$ & 3 & 15.79 & Howrah, Barddhaman and Nadia \\
Low & $50-55$ & 4 & 21.06 & East and West Medinipur, Bankura and Darjeeling \\
Very low & Below 50 & 9 & 47.37 & $\begin{array}{l}\text { South 24 Parganas, Birbhum, Purulia, Malda, Murshidabad, } \\
\text { Uttar Dinajpur, Dakshin Dinajpur, Jalpaiguri and Cooch } \\
\end{array}$ \\
\hline
\end{tabular}

Nadia have a medium-to-very high range (> 31\%) of development, as they record high percentages of COVID19 cases. By contrast, approximately $68 \%$ of the districts have low-to-very low levels of development and number of COVID-19 cases (Fig. 20).

Moreover, the corresponding relationship between the percentage of the urban population (taken as an independent variable) and the percentage of COVID-19 cases (taken as a dependent variable) of all the districts of West Bengal was calculated using the residual method. The calculated values were categorised into five groups as tabulated.

Table 4 depicts a strong corresponding relationship between the concentration of urban population and COVID19 attack, as a very high residual value ( $>4)$ covers more than $63 \%$ of the districts; most are concentrated in the southern part and few are located in the northern part of West Bengal (Fig. 21). A medium level of relationship (approximately 11\%) is observed in centrally located Malda and Murshidabad; meanwhile, a low level of relationship is found in the western districts, which cover approximately $26 \%$ of the total. A negligible connection is also noticed in the remotely located and dissected islands of South 24 Parganas.

Population density (per $\mathrm{km}^{2}$ ) has a great nexus with the COVID-19 cases, as densely populated areas raise the risk of great physical contact amongst people and can spread the virus. The observation of COVID-19 cases, infection rates and death cases reveal that the urban areas of West Bengal are particularly most vulnerable, as they are the initial centre of the outbreak. The prevalence of slums within cities specifically raises the risk of this viral transmission. Thus, Kolkata is at its peak and is becoming a hot spot for further spreading. In West Bengal, an economically wealthy section can make good arrangements for rigid interventions, such as lockdown, whilst poor people may be forced to go out to arrange food supplies. Moreover, accessing meals from community kitchens, receiving food items from donations and buying essential items from government fair shops elevate the probability of the less economically well-off sections catching the infection. Therefore, the spatial concentration of population density, percentage of urban population and COVID-19 cases in all the districts of West Bengal were 
Fig. 20 Levels of development and proportion of COVID-19 cases in West Bengal

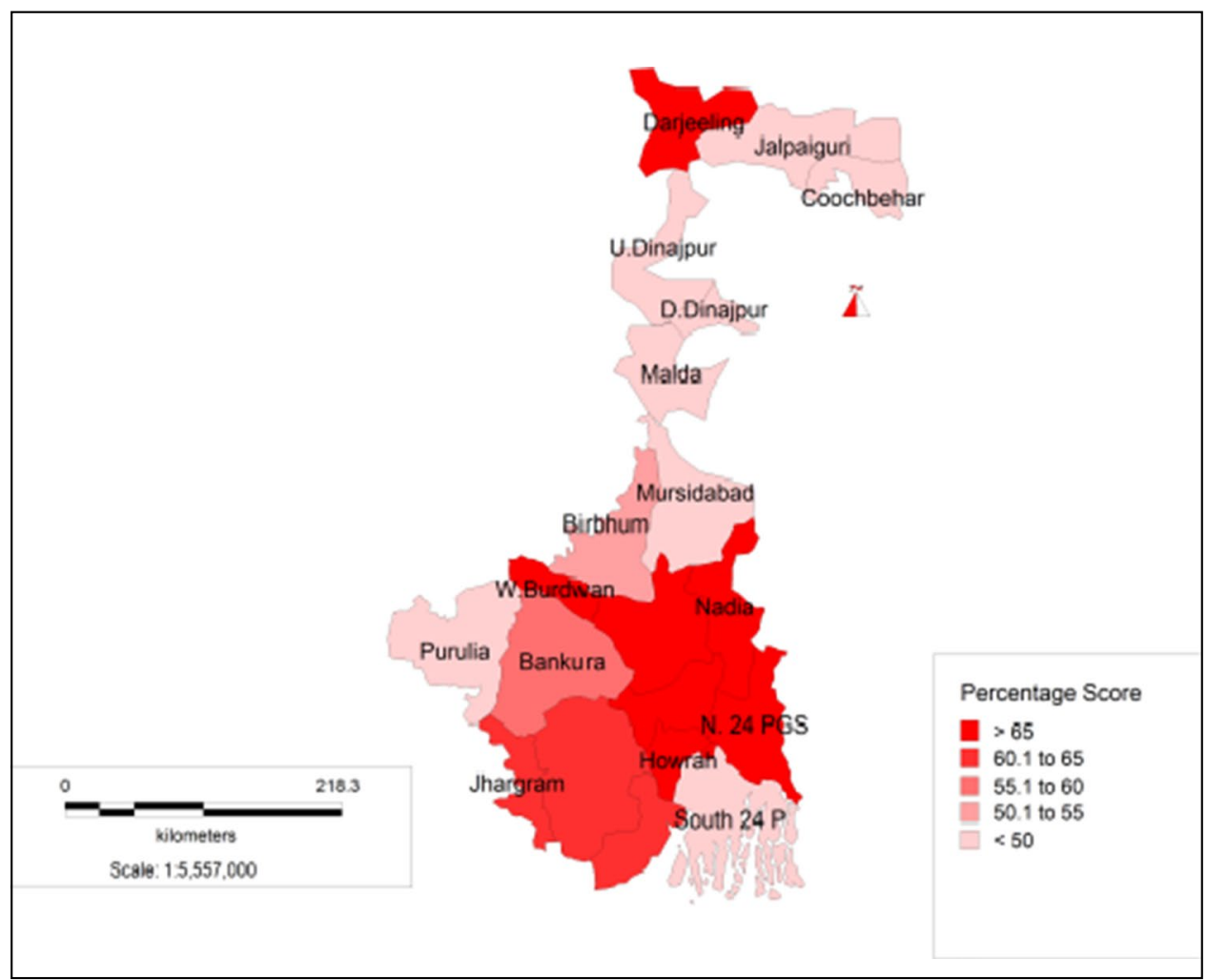

Table 4 Corresponding relationship between urban population and COVID-19 cases

\begin{tabular}{lllll}
\hline Category & Residual & No. of districts & $\begin{array}{l}\text { Percentage of total } \\
\text { districts }\end{array}$ & District \\
\hline Very high & Above 6 & 8 & 42.10 & $\begin{array}{c}\text { Kolkata, Howrah, Hooghly, North 24 Parganas, South 24 Parga- } \\
\text { nas, Barddhaman, Nadia and Darjeeling } \\
\text { Jalpaiguri, Cooch Behar, East and West Medinipur }\end{array}$ \\
High & $4-6$ & 4 & 21.05 & Malda and Murshidabad \\
Medium & $3-4$ & 2 & 10.52 & Uttar Dinajpur, Dakshin Dinajpur, Birbhum Bankura and Purulia \\
Low & $2-3$ & 5 & 26.32 & Islands of South 24 Parganas \\
Very low & Below 2 & - & Negligible &
\end{tabular}

analysed by using a location quotient method, as it represents ratios that are plotted on a graph (Fig. 22), which signifies some significant connections amongst these variables. Districts in the southern region, such as Kolkata, North 24 Parganas, Howrah, Hooghly, Nadia and Bardhaman have high values with respect to the overall state values. Most districts in the northern and western regions have low concentrations of these variables, except Darjeeling.

\section{Discussion}

The COVID-19 pandemic and related issues affect the world in various scales from small to large, and the regions based on their background adjust to the situation to cope up and overcome it (Headey et al. 2020; Cui et al. 2021; Tittonell et al. 2021; Risendal et al. 2021). The diverse sectors of each country and within several micro administrative regions make decisions to reduce the spread of COVID-19 and there lies the need for the assessment of various socioeconomic, infrastructural and environmental sectors (Rahman et al. 2020; Lopez and Neely 2021; Hotle and Mumbower 2021). Thus, an assessment of the same sectors for the state of West Bengal, which belongs to a developing country, that is, India, was conducted in the current study (Kalluri et al. 2021; Dutta and Fischer 2021). The research thoroughly followed the hypotheses and research questions, which have not been addressed before. Thereafter, how and when the COVID-19 situation started in India and West Bengal, in particular, was observed and 
Fig. 21 Relationship between urban population and COVID19 cases in West Bengal
Fig. 22 Spatial concentration of population density, urban population and COVID-19 cases in West Bengal
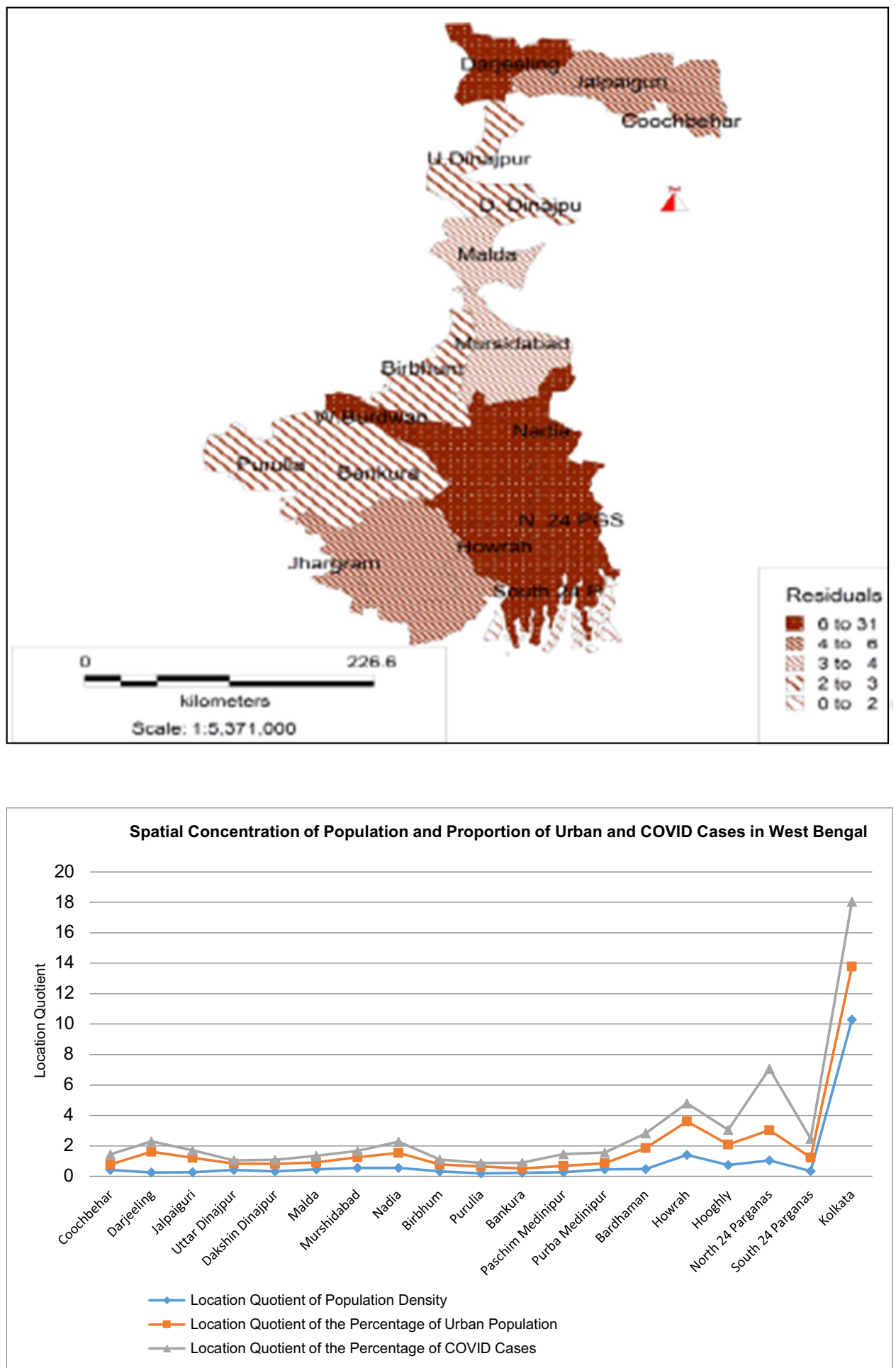

discussed, followed by the district level affection rates for micro-level scrutiny. The economic sector was probably the most affected throughout the world due to such nationwide lockdown and related consequences; henceforth, the economic sector and employment situation of West Bengal were investigated thoroughly (Goswami et al. 2021). The movement of people of the study area and the country was also seriously hampered and restricted for a long period, which had some serious consequences. These consequences had been addressed in this research. The connection of the impacts of these sectors to infrastructural sectors, such as transport and communication, education and health sectors was also observed. District-wise, active cases, death cases, discharge of COVID-19, related health 
impacts on people and their re-connections with associated stakeholders to primary to quandary sectors were also discussed; in addition, how the budget of the state was impacted or connected and how import and export sectors became affected were addressed. Students in schools, colleges and universities were seriously affected, and some ground-level observations were conducted through the primary survey. Moreover, people's adjustment to the situation amidst the several difficulties and challenges they faced was portrayed in the current effort. In addition, the environmental sectors were covered in the study, as this aspect is also important when analysing state overview from various aspects. The hygienic practice of the people, their awareness, patience and adjustment capacity with pandemic and lockdown circumstances were also observed during the study. All these aspects were not investigated in a single attempt as of now, especially for West Bengal. Thus, the current effort is trying to contribute scientifically with some serious efforts and can shed some light on the highlighted issues that will definitely help find the future road map of the state for sustainable development and management.

As no study is available for multi-sectoral impact assessment due to COVID-19 in West Bengal or similar other regions of the country, we plan to depict such kind of study. Some researchers (Srivastava et al. 2020; Otmani et al. 2020; Tobías et al. 2020; Staples et al. 2020) have assessed the impact of the COVID-19 lockdown on air quality, tourism, education and economy on the basis of satellite and conventional data by using statistical and GIS techniques from a regional to a global scale. Headey et al. (2020) studies have also observed the changes in air quality in the municipal corporation of Kolkata and Howrah, West Bengal before and during lockdown by using GIS techniques. The statistical method was also (analysis of variance) applied to the changing association of the pollutants. In another work, Sarkar et al. (2020) evaluated the significant decrease in lighting activities due to the COVID-19 pandemic in the megacity of Kolkata, West Bengal. They considered the impact on air pollutants (i.e. suspended particulate matter and NO2) before and during the lockdown in the urban megacity of Kolkata. The pollutant rate decreased by more than $40 \%$ from the pre-lockdown period. Bera et al. (2020) found some significant impacts of the COVID-19 lockdown on urban air pollution in Kolkata, as they revealed a noteworthy decrease of pollutants such as $\mathrm{CO}, \mathrm{NO}_{2}$ and $\mathrm{SO}_{2}$, whereas the average level of $\mathrm{O} 3$ slightly increased during the lockdown. Moreover, Mahato and Ghosh, (2020) investigated the short-term exposure to the ambient air quality of the most polluted Indian cities due to the lockdown. They found that $\mathrm{CO}$ and $\mathrm{NO} 2$ reduced to approximately $30 \%$ and 57\%, respectively; the $\mathrm{PM}_{10}$ and $\mathrm{PM}_{2.5}$ concentrations also suppressed below the permissible limit in all cities during the lockdown period. Mishra et al. (2020) developed the
COVID-19 Vulnerability Index by using Analytical Hierarchical Process whilst studying urban vulnerability in India. Ghosh and Sarkar (2020) worked on the impact of COVID-19 on maternal mental health and questionable healthcare services in rural India and found that childbirth is taking place at the rural home. Chakraborti et al. (2020b) used machine learning in exploring the determinant factors of the pandemic and found that air pollution, migration, economic and demographic factors are the most momentous controlling factors. Arif and Sengupta (2020) found a nexus between the spatial distribution of population density and COVID-19 pandemic in the south Indian states by using the geo-statistical approach.

Saha et al. (2020) analysed the COVID-19 Community Mobility Reports 2020 to determine the mobility trends over time during the pre- and post-lockdown periods across different categories of places such as retail and recreation, groceries and pharmacies, parks, transit stations, workplaces and residential areas. Kumar et al. (2020) attempted to use a mathematical model and predict COVID-19 infection in India. They also conducted a correlation analysis of the virus transmission with socioeconomic factors, such as state-wise population, gender ratio, rural-urban ratio, literacy rate and GDP, and prepared a long-term prediction of cumulative cases, spreadability rate and pandemic peak in India. Some researchers have assessed the impact of COVID-19 lockdown on UG and OG students of different colleges and universities of West Bengal. They have conducted a survey of a structured questionnaire for learning status using Google Forms through WhatsApp and email. They have observed that several students attend e-learning programmes by using their android mobile phones. Thus, they face depression, anxiety, poor Internet connectivity and an unfavourable study environment. Kapasia et al. (2020) studied the status of learning system and tried to show the need and importance of setting up proper strategies for an effective learning system in the pandemic situation.

However, life has become stagnant and boring due to the lockdown and stay-at-home setting that is continuously practiced for such a long period; due to such prolonged empathy, people have become victims of depression and are under huge mental pressure (Khan et al. 2020; Hsu et al. 2020; Lin et al. 2021; Zhong et al. 2020). This situation often leads to some drastic steps for many people, as they continuously fear the sufferings caused by COVID-19. People also become vulnerable due to the panic caused by death. People suffer from anxiousness and confusion due to the lack of knowledge and information about the nature of the virus and its attack. They are also concerned about the timely healthcare facilities. Children are probably the worst sufferers due to such a pandemic. Not being able to go to school physically and instead attending online classes bring some extra pressure to their pleasure and playful lives. Students of higher education are also facing the pressure of online 
classes and examinations. They become victims of mental stress and depression. The work-from-home situation creates some added pressure to those who have jobs. Meanwhile, the jobless are in a pathetic situation, which aggravates the overall situation. Some people commit suicide, as they cannot cope up with the situation. News about COVID-19 and deaths due to the virus are seen on social media and news channels, and such news makes people more depressed and causes further panic. Moreover, disabled individuals along with their families face various unfavourable challenges of maintaining their household chores and routinely make them more nervous and anxious. The unawareness and insufficient or inappropriate information and some baseless rumours likely affect the mental well-being of people during this pandemic (Buckley and Westaway 2020). Yoga, meditation and exercise help control the situation. Several webinars, which aim to explain the importance of yoga and meditation for personal development, are also held for stress management in India. Fortunately, adults participate and present in such webinars; according to them, these webinars are beneficial (Sun and Zhai 2020).

S`ommon people. Examples of these words are quarantine, social distancing and isolation. Thus, people are becoming increasingly aware of personal hygiene and how to maintain it. Some of the issues related to it are listed below:

i.People wash their hands frequently and regularly by using hand wash, soap or an alcohol-based sanitizer.

ii.People avoid touching their eyes, nose and mouth that is frequently done unconsciously, as they become aware of the fact that the virus can transfer from hands to eyes, mouth or nose.

iii.The use of dissolved paper, spray and sanitizer has increased at a faster and more intensified rate than before.

iv.People take medical care in case they have difficulty in breathing, a cough, fever and related sickness.

v.Gathering and overcrowding have reduced, and people are concerned regarding this matter.

vi.As the risk factor is high in the case of infants, adolescences and old-age people, they take extra caution and care and thus are willing to stay home.

vii.Most people seek good behaviour to prevent COVID-19 infection. They also try to maintain hygiene practice.

Still, improvements in the understanding of epidemiology, transmission, treatment and methods of control should be strengthened to obtain better results in health and hygiene. The testing facility of COVID-19, at the initial phase, was not satisfactory. Fortunately, it was later increased to the desired level. However, a large proportion of people are not maintaining the social distancing properly. Moreover, the role played by the government for migration laborers is not satisfactory. The outcomes of the current effort and the hopeful possibilities are tabulated below (Table 5), which is self-explanatory and gives a glimpse of the impact of COVID-19.

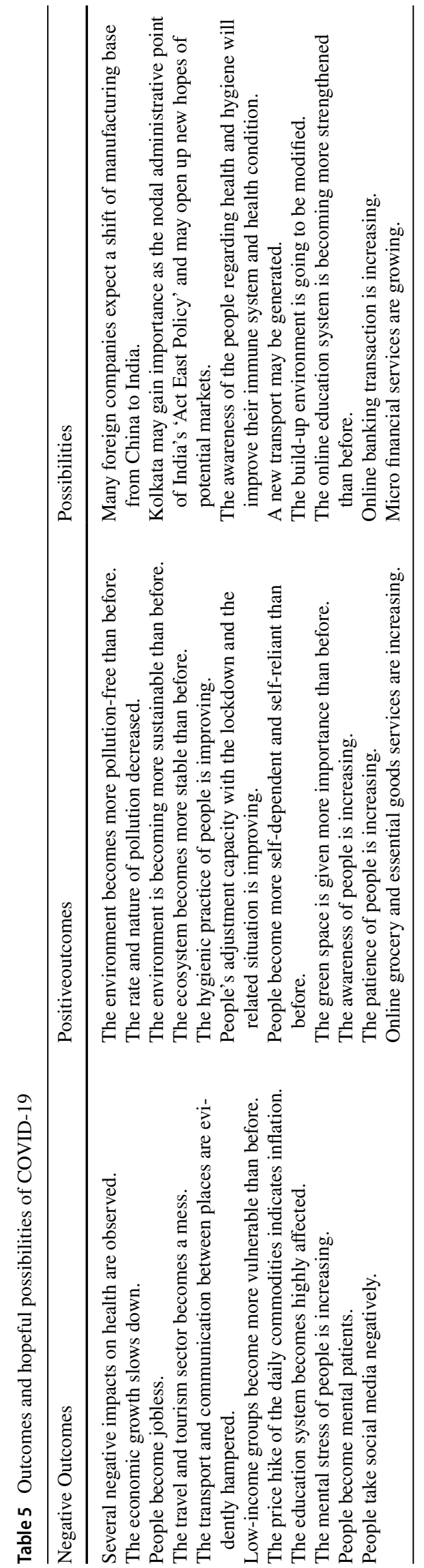


The categorisation of the districts into three zones (red, orange and green) and strong control and observation helps the government in controlling the spread of COVID-19. With such initiation and night curfew, strict control on social distancing, frequent sanitization of the market places, and crowing areas, circulating norms and protocols, awareness campaign, opening of the control room and toll-free helpline number, etc. help to manage the pandemic situation. Probably thus, the percentage of COVID-19 cases to the total population in the state is lower $(0.618)$ than the national average $(0.843)$ in the 1 st wave. Moreover, the government has strengthened its e-governance during the lockdown period, build up Integrated Covid Management System (WB-ICMS) and launched an app named 'Sandhane' (Search) to support community health workers, like Accredited Social Health Activists (ASHA) in tracing COVID-19 suspects in rural and remote areas. Therefore, it reveals that the state government managed to cope up with the situation with a good recovery rate and low death rate, and all these government initiatives were followed more strictly starting from the 2 nd wave of the pandemic in the state. The notable insights from the current study will definitely help to expand survival instincts to develop a viable society with sustainable management in the future.

\section{Conclusions}

The study concludes that the sector-wise assessment of the impact of COVID-19 in West Bengal is multidimensional and diverse by nature. It also reveals that the economic progress and/or growth has slowed down; many people have become jobless, and the engagement in various employments has stopped; daily wage labourers of the state have left their workplace and returned home; most people have no sufficient money for their daily livelihood; the movement of people and commodities has stopped or slowed down; businesses or imports-exports have been hampered largely; the travel and tourism sector has stopped operating; employees and stakeholders related to the tourism sector are facing tremendous troubles. Moreover, the price hike of the daily essential commodities makes poor people further vulnerable; students are becoming restless, as the conventional education system has collapsed; the physical and mental health of people are worsening day by day; a large proportion of people have become mental patients; many people have panic attacks; and a kind of health hazard is occurring. West Bengal is generally known as a diverse state in terms of its physical environment, population base, occupation and culture; economic diversity; and bordering with national and international boundaries. West Bengal is also popular for its tourism. However, the selected sectors have been severely affected, and the state needs ample time to rebuild its state of affairs, prosperity and diversity. Therefore, this kind of assessment is necessary for the future road map of activity and planning for the sustainable management of the state. The state is fighting with the pandemic situation and continuously tries not only to cope up with the situation, but also to develop by managing the situation. Calculating the time to control the situation and inculcate the possible way out is probably too early, as the vaccine is still unavailable in the market today. In this study, the sample survey was conducted with a comparatively small sample size by using the English language, and that can be considered a limitation of the current effort, especially for the sector where it was applied. The unavailability of the COVID-19 impact database on the chosen sectors was felt during the investigation. If the observed situation can be judged by some secondary data analysis and/or by incorporating primary surveyed data, then this study can shed more light on the strategy to set the future planning and management. Still, the current effort is very much useful as all the analyses and observations are authentic. This factor can be treated as an initial attempt at such a kind of study. It can definitely show the path of future research and open up a new direction of COVID-19 impact analysis. The COVID-19 pandemic in West Bengal is very drastic, as the state has a large population base and over-dependency on Kolkata for various purposes. Nevertheless, the state executes the proper decision of lockdown and takes the help of expert doctors to treat COVID-19 patients with a good recovery rate and a low death rate. Despite the environmental sectors, a strong, negative and adverse effect is observed on other sectors. Nevertheless, the state is good enough to cope up with the situation. However, an anomaly is still present, and people are afraid to think about the future growth and development of the state. The deficiency of data for statistical analysis and impact assessment was felt during the investigation. Therefore, the preparation of a proper databank for in-depth assessment is needed to inculcate proper management and planning. The outcomes from the study can help identify the thrust area to give strength and to determine the possible method for planning and management.

\section{Data availability statement}

COVID-19 data is available at http://www.covid19india.org and https://covidindia.org/west-bengal.

Supplementary Information The online version contains supplementary material available at https://doi.org/10.1007/s12517-021-08836-z.

Funding This work was supported by the Researchers Supporting Project (Grant no. number RSP-2021/14), King Saud University, Riyadh, Saudi Arabia.

Code availability Not applicable 


\section{Declarations}

Ethics approval Not applicable

Consent to participate Not applicable

Consent for publication All the authors give consent for the publication.

Conflict of interest The authors declare that they have no competing interests.

\section{References}

Abdullah M, Dias C, Muley D, Shahin, M (2020) Exploring the impacts of COVID-19 on travel behavior and mode preferences. Transportation Research Interdisciplinary Perspectives 100255

Abu-Rayash A, Dincer I (2020) Analysis of mobility trends during the COVID-19 coronavirus pandemic: exploring the impacts on global aviation and travel in selected cities. Energy Res Soc Sci 68:101693

Acharya R, Porwal A (2020) A vulnerability index for the management of and response to the COVID-19 epidemic in India: an ecological study. Lancet Glob Health 8(9):e1142-e1151

Arif M, Sengupta S (2020) Nexus between population density and novel coronavirus (COVID-19) pandemic in the south Indian states: a geo-statistical approach. Environment, Development and Sustainability 1-29

Barman MP, Rahman T, Bora K, Borgohain C (2020) COVID-19 pandemic and its recovery time of patients in India: a pilot study. Diabetes Metab Syndr: Clin Res Rev 14(5):1205-1211

Beck MJ, Hensher DA (2020) Insights into the impact of Covid-19 on household travel, working, activities and shopping in Australiathe early days under restrictions. Transp Policy 96:76-93

Bera B, Bhattacharjee S, Shit PK, Sengupta N, Saha, S (2020) Significant impacts of COVID-19 lockdown on urban air pollution in Kolkata (India) and amelioration of environmental health. Environment, Development and Sustainability 1-28

Bose S (2015) State and management of architectural heritage in Kolkata. J Archit Conserv 21(3):178-194

Buckley R, Westaway D (2020) Mental health rescue effects of women's outdoor tourism: a role in COVID-19 recovery. Ann Tour Res 85:103041

Bukhari Q, Jameel Y (2020) Will coronavirus pandemic diminish by summer? Available at SSRN 3556998, from https://ssrn.com/ abstract=3556998 orhttps://doi.org/10.2139/ssrn.3556998

Chakraborti S, Maiti A, Pramanik S, Sannigrahi S, Pilla F, Banerjee A, Das DN (2020) Evaluating the plausible application of advanced machine learnings in exploring determinant factors of present pandemic: a case for continent specific COVID-19 analysis. Science of the Total Environment 142723

Chowdhuri I, Pal SC, Saha A, Chakrabortty R, Ghosh M, Roy P (2020) Significant decrease of lightning activities during COVID-19 lockdown period over Kolkata megacity in India. Sci Total Environ 747:141321

Cui Q, He L, Liu Y, Zheng Y, Wei W, Yang B, Zhou M (2021) The impacts of COVID-19 pandemic on China's transport sectors based on the CGE model coupled with a decomposition analysis approach. Transport Policy 103:103-115

Dutta A, Fischer HW (2021) The local governance of COVID-19: disease prevention and social security in rural India. World Dev $138: 105234$
Ghosh A, Sarkar S (2020) The coronavirus (COVID-19) pandemic's impact on maternal mental health and questionable health care services in rural India. Int J Health Plann Manag 35(6): 1626-1628

Goswami R, Roy K, Dutta S, Ray K, Sarkar S, Brahmachari K, Majumdar K (2021) Multi-faceted impact and outcome of COVID-19 on smallholder agricultural systems: integrating qualitative research and fuzzy cognitive mapping to explore resilient strategies. Agric Syst 189:103051

Headey D, Heidkamp R, Osendarp S, Ruel M, Scott N, Black R, Walker N (2020) Impacts of COVID-19 on childhood malnutrition and nutrition-related mortality. Lancet 396(10250):519-521

Hotle S, Mumbower S (2021) The impact of COVID-19 on domestic US air travel operations and commercial airport service. Transp Res Interdiscip Perspect 9:100277

Hsu CH, Lin HH, Wang CC, Jhang S (2020) How to defend COVID19 in Taiwan? Talk about people's disease awareness, attitudes, behaviors and the impact of physical and mental health. Int J Environ Res Public Health 17(13):4694

Kalluri ROR, Gugamsetty B, Tandule CR, Kotalo RG, Thotli LR, Rajuru RR, Palle SNR (2021) Impact of aerosols on surface ozone during COVID-19 pandemic in southern India: A multiinstrumental approach from ground and satellite observations, and model simulations. J Atmos Solar-terr Phys 212:105491

Kanitkar T (2020) The COVID-19 lockdown in India: impacts on the economy and the power sector. Glob Transit 2:150-156

Kapasia N, Paul P, Roy A, Saha J, Zaveri A, Mallick R, Chouhan P (2020) Impact of lockdown on learning status of undergraduate and postgraduate students during COVID-19 pandemic in West Bengal India. Child Youth Serv Rev 116:105194

Karar K, Gupta AK, Kumar A, Biswas AK (2006) Characterization and identification of the sources of chromium, zinc, lead, cadmium, nickel, manganese and iron in PM 10 particulates at the two sites of Kolkata India. . Environ Monit Assess 120(1):347-360

Khan AH, Sultana MS, Hossain S, Hasan MT, Ahmed HU, Sikder MT (2020) The impact of COVID-19 pandemic on mental health \& wellbeing among home-quarantined Bangladeshi students: a cross-sectional pilot study. J Affect Disord 277:121-128

Kreiner NC, Ram Y (2020) National tourism strategies during the Covid-19 pandemic. Ann Tour Res 103076. https://doi.org/10. 1016/j.annals.2020.103076

Kumar A, Rani P, Kumar R, Sharma V, Purohit SR (2020) Data-driven modelling and prediction of COVID19 infection in India and correlation analysis of the virus transmission with socio-economic factors. Diabetes Metab Syndr 14(5):1231-1240

Kumar S (2020) Effect of meteorological parameters on spread of COVID-19 in India and air quality during lockdown. Sci Total Environ 745:141021

Kumaran M, Geetha R, Antony J, Vasagam KK, Anand PR, Ravisankar T, Vijayan KK (2020) Prospective impact of Corona virus disease (COVID-19) related lockdown on shrimp aquaculture sector in India-a sectoral assessment. Aquaculture 531:735922

Li J, Tartarini F (2020) Changes in air quality during the COVID19 lockdown in Singapore and associations with human mobility trends. Aerosol Air Qual Res 20(8):1748-1758

Lin HH, Ling Y, Lin JC, Liang ZF (2021) Research on the development of religious tourism and the sustainable development of rural environment and health. Int J Environ Res Public Health 18(5):2731

Lopez PJ, Neely AH (2021) Fundamentally uncaring: The differential multi-scalar impacts of COVID-19 in the US. Soc Sci Med 272:113707

Mahato S, Ghosh KG (2020) Short-term exposure to ambient air quality of the most polluted Indian cities due to lockdown amid SARSCoV-2. Environ Res 188:109835

Mishra SV, Gayen A, Haque SM (2020) COVID-19 and urban vulnerability in India. Habitat Int 103:102230 
Ng JH, Hirsch JS, Wanchoo R, Sachdeva M, Sakhiya V, Hong S, Barnett RL (2020) Outcomes of patients with end-stage kidney disease hospitalized with COVID-19. Kidney Int 98(6):1530-1539

Otmani A, Benchrif A, Tahri M, Bounakhla M, El Bouch M, Krombi MH (2020) Impact of Covid-19 lockdown on PM10, SO2 and NO2 concentrations in Salé City (Morocco). Sci Total Environ 735:139541

Rahman MA, Zaman N, Asyhari AT, Al-Turjman F, Bhuiyan MZA, Zolkipli MF (2020) Data-driven dynamic clustering framework for mitigating the adverse economic impact of Covid-19 lockdown practices. Sustain Cities Soc 62:102372

Rahman MS, Das GC (2021) Effect of COVID-19 on the livestock sector in Bangladesh and recommendations. J Agric Food Res 4:100128

Ranjan AK, Patra AK, Gorai AK (2020) Effect of lockdown due to SARS COVID-19 on aerosol optical depth (AOD) over urban and mining regions in India. Sci Total Environ 745:141024

Risendal B, Hébert JR, Morrato EH, Thomson CA, Escoffery CN, Friedman DB, Wheeler SB (2021) Addressing COVID-19 using a public health approach: perspectives from the cancer prevention and control research network. American Journal of Preventive Medicine 60(6):877-882

Rumbach A (2017) At the roots of urban disasters: planning and uneven geographies of risk in Kolkata India. J Urban Aff 39(6):783-799

Saha J, Barman B, Chouhan P (2020) Lockdown for COVID-19 and its impact on community mobility in India: an analysis of the COVID-19 Community Mobility Reports 2020. Child Youth Serv Rev 116:105160

Sarkar M, Das A, Mukhopadhyay S (2020) Assessing the immediate impact of COVID-19 lockdown on the air quality of Kolkata and Howrah, West Bengal, India. Environment, Development and Sustainability 1-30

Schulte-Schrepping J, Reusch N, Paclik D, Baßler K, Schlickeiser S, Zhang B, De Domenico E (2020) Severe COVID-19 is marked by a dysregulated myeloid cell compartment. Cell 182(6):1419-1440
Shehzad K, Sarfraz M, Shah SGM (2020) The impact of COVID-19 as a necessary evil on air pollution in India during the lockdown. Environ Pollut 266:115080

Sigala M (2020) Tourism and COVID-19: impacts and implications for advancing and resetting industry and research. J Bus Res 117:312-321

Srivastava S, Kumar A, Bauddh K, Gautam AS, Kumar S (2020) 21-day lockdown in India dramatically reduced air pollution indices in Lucknow and New Delhi, India. Bull Environ Contam Toxicol 105:9-17

Staples L, Nielssen O, Kayrouz R, Cross S, Karin E, Ryan K, Titov N (2020) Rapid Report 2: symptoms of anxiety and depression during the first 12 weeks of the Coronavirus (COVID-19) pandemic in Australia. Internet Interventions 100351

Sun C, Zhai Z (2020) The efficacy of social distance and ventilation effectiveness in preventing COVID-19 transmission. Sustain Cities Soc 62:102390

Tittonell P, Fernandez M, El Mujtar VE, Preiss PV, Sarapura S, Laborda CIM (2021) Emerging responses to the COVID-19 crisis from family farming and the agroecology movement in Latin America-a rediscovery of food, farmers and collective action. Agric Syst 190:103098

Tobías A, Carnerero C, Reche C, Massagué J, Via M, Minguillón MC, Querol X (2020) Changes in air quality during the lockdown in Barcelona (Spain) one month into the SARS-CoV-2 epidemic. Sci Total Environ 726:138540

Uğur NG, Akbıyık A (2020) Impacts of COVID-19 on global tourism industry: a cross-regional comparison. Tour Manag Perspect 36:100744

Walter D (2020) Implications of Covid-19 for labour and employment in India. The Indian Journal of Labour Economics 1-5

Zhong B, Huang Y, Liu Q (2020) Mental health toll from the coronavirus: Social media usage reveals Wuhan residents' depression and secondary trauma in the COVID-19 outbreak. Comput Hum Behav 114:106524 